\title{
LN-Derived Fibroblastic Reticular Cells and Their Impact on T Cell Response-A Systematic Review
}

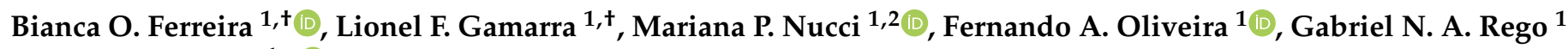 \\ and Luciana Marti $1, *$ (D) \\ 1 Department of Experimental Research, Hospital Israelita Albert Einstein, São Paulo 05652-000, Brazil; \\ bianca.oliveira@einstein.br (B.O.F.); lionel.gamarra@einstein.br (L.F.G.); mariana.nucci@hc.fm.usp.br (M.P.N.); \\ fernando.anselmo@einstein.br (F.A.O.); gabriel.nery@einstein.br (G.N.A.R.) \\ 2 LIM44-Hospital das Clínicas da Faculdade Medicina da Universidade de São Paulo, \\ São Paulo 05403-000, Brazil \\ * Correspondence: luciana.marti@einstein.br; Tel.: +55-11-2151-1353 \\ + These authors contributed equally to this work.
}

check for updates

Citation: Ferreira, B.O.; Gamarra, L.F.; Nucci, M.P.; Oliveira, F.A.; Rego, G.N.A.; Marti, L. LN-Derived Fibroblastic Reticular Cells and Their Impact on T Cell Response-A Systematic Review. Cells 2021, 10, 1150. https://doi.org/10.3390/ cells10051150

Academic Editors: Paul V. Lehmann and Abdelhadi Saoudi

Received: 7 March 2021

Accepted: 23 April 2021

Published: 10 May 2021

Publisher's Note: MDPI stays neutral with regard to jurisdictional claims in published maps and institutional affiliations.

Copyright: (C) 2021 by the authors Licensee MDPI, Basel, Switzerland. This article is an open access article distributed under the terms and conditions of the Creative Commons Attribution (CC BY) license (https:// creativecommons.org/licenses/by/ $4.0 /)$.

\begin{abstract}
Fibroblastic reticular cells (FRCs), usually found and isolated from the T cell zone of lymph nodes, have recently been described as much more than simple structural cells. Originally, these cells were described to form a conduit system called the "reticular fiber network" and for being responsible for transferring the lymph fluid drained from tissues through afferent lymphatic vessels to the $\mathrm{T}$ cell zone. However, nowadays, these cells are described as being capable of secreting several cytokines and chemokines and possessing the ability to interfere with the immune response, improving it, and also controlling lymphocyte proliferation. Here, we performed a systematic review of the several methods employed to investigate the mechanisms used by fibroblastic reticular cells to control the immune response, as well as their ability in determining the fate of $\mathrm{T}$ cells. We searched articles indexed and published in the last five years, between 2016 and 2020, in PubMed, Scopus, and Cochrane, following the PRISMA guidelines. We found 175 articles published in the literature using our searching strategies, but only 24 articles fulfilled our inclusion criteria and are discussed here. Other articles important in the built knowledge of FRCs were included in the introduction and discussion. The studies selected for this review used different strategies in order to access the contribution of FRCs to different mechanisms involved in the immune response: $21 \%$ evaluated viral infection in this context, 13\% used a model of autoimmunity, $8 \%$ used a model of GvHD or cancer, $4 \%$ used a model of Ischemic-reperfusion injury (IRI). Another four studies just targeted a particular signaling pathway, such as MHC II expression, FRC microvesicles, FRC secretion of IL-15, FRC network, or ablation of the lysophosphatidic acid (LPA)-producing ectoenzyme autotaxin. In conclusion, our review shows the strategies used by several studies to isolate and culture fibroblastic reticular cells, the models chosen by each one, and dissects their main findings and implications in homeostasis and disease.
\end{abstract}

Keywords: fibroblastic reticular cells; T cells; lymph nodes

\section{Introduction}

Lymph node structural organization is reported to be governed by the stromal cells [1]. Fibroblast reticular cells (FRCs), a subset of the stromal cells found in the T lymphocyte region of lymph nodes (LNs) and other secondary lymphoid organs (SLOs), have been described as much more than structural cells [2].

FRCs are described to be organized in a conduit system called the "reticular fiber network", responsible for transferring antigens from tissue to T cell zones in LNs and for controlling the conduit matrix deposition during lymph node expansion [3,4].

Their ability for cytokine and chemokine production has been demonstrated in several studies $[2,5,6]$, and their relevant multifunctional roles and multiple subsets have been 
previously defined [7]. In addition, mice and human lymph node-derived FRC's ability to react to inflammatory stimuli has been described [8-10].

Moreover, a few studies have implicated FRC in peripheral tolerance. Certain stromal cells can express antigens from peripheral tissues (PTA) and mediate the maintenance of peripheral tolerance through the deletion of self-reactive T cells and other mechanisms [11-16]. In addition, other cells previously known as structural cells, such as epithelium, endothelium, and fibroblasts, have also been implicated as players in the immune response [17].

However, there are several obscure points in FRC biology that need elucidation, mainly that of their dual role augmenting and, thereby, controlling the immune response. In this sense, this systematic review lists several FRC mechanisms described as controlling mechanisms of the immune response [18-41].

The articles reviewed here report on using several animal models of disease and /or genetically modified mice as tools to investigate FRCs' effect on T cells. These articles also approach and clarify the mechanisms involved in $\mathrm{T}$ cell proliferation or differentiation in subsets with regulatory, effector, or memory profiles [18-41]. In addition, these articles reported the markers used to identify and isolate FRCs, as well as the methods used for these cells' cultivation.

Lately, FRCs' ability for controlling the immune response and its role in several pathological conditions, such as viral infection, inflammation, metastatic cancer, and autoimmunity, are also included in this review. Consequently, we comprise here the latest updates in FRC biology, their impact on T cell fate, how they participate in diseases, and how they could be manipulated in order to ameliorate the course of certain conditions.

\section{Materials and Methods}

\subsection{Search Strategy}

As a search strategy, the only articles included were indexed and published in the last five years, including between 2016 and 2020, in PubMed, Scopus, and Cochrane, following the PRISMA guidelines [42]. The next criteria of interest selected were keywords in the following sequence: (Fibroblastic Reticular Cell OR Fibroblastic Reticular Cells) AND (Lymph Node OR Lymph Nodes) AND (T cell OR T cells).

In addition, the following Boolean operators (DecS/MeSH) were used:

SCOPUS: (TITLE-ABS-KEY ("fibroblastic reticular cells") OR TITLE-ABS-KEY ("fibroblastic reticular cell")) AND (TITLE-ABS-KEY ("lymph node") OR TITLE-ABS-KEY ("lymph nodes")) AND (TITLE-ABS-KEY (t-cell) OR TITLE-ABS-KEY (t-cells) OR TITLEABS-KEY ("T cell”) OR TITLE-ABS-KEY ("T cells") OR TITLE-ABS-KEY ("T lymphocyte") OR TITLE-ABS-KEY ("T lymphocytes")) AND (LIMIT-TO (DOCTYPE, "ar")) AND (LIMITTO (PUBYEAR, 2020) OR LIMIT-TO (PUBYEAR, 2019) OR LIMIT-TO (PUBYEAR, 2018) OR LIMIT-TO (PUBYEAR, 2017) OR LIMIT-TO (PUBYEAR, 2016)).

PubMed: (“T cell”[Title/Abstract]) OR ("T cells"[Title/Abstract]) OR ("T-cell"[Title/ Abstract]) OR ("T-cells"[Title/Abstract]) OR ("T-lymphocyte"[Title/Abstract]) OR ("Tlymphocytes"[Title/Abstract])) AND (y_5(Filter)) AND (ffrft(Filter)) AND (fha(Filter)) AND (journalarticle(Filter)) AND (fft(Filter)) AND (("fibroblastic reticular cells"[Title/ Abstract]) OR ("fibroblastic reticular cell"[Title/Abstract]) OR (FRC[Title/Abstract]) OR (FRCs[Title/Abstract])) AND (y_5(Filter)) AND (ffrft(Filter)) AND (fha(Filter)) AND (journalarticle(Filter)) AND (fft(Filter)) AND (("lymph node"[Title/Abstract]) OR ("lymph nodes"[Title/Abstract]) OR ("secondary organs"[Title/Abstract])) AND (y_5(Filter)) AND (ffrft(Filter)) AND (fha(Filter)) AND (journalarticle(Filter)) AND (fft(Filter)) Filters: Abstract, Free full text, Full text, Journal Article, in the last 5 years.

Cochrane: "fibroblastic reticular cells" in Title Abstract Keyword OR "fibroblastic reticular cell" in Title Abstract Keyword AND "lymph node" in Title Abstract Keyword OR "lymph nodes" in Title Abstract Keyword AND "T cell" in Title Abstract Keyword—word variations were searched. 


\subsection{Inclusion Criteria}

This review included only original articles published between 2016 and 2020, and written in the English language. The following inclusion criteria were used: (i) studies in vitro and/or in vivo using fibroblastic reticular cells on a homeostatic or stimulated state and their impact on T cell function; (ii) studies of network analysis of homeostatic or stimulated fibroblastic reticular cells and their impact in $\mathrm{T}$ cell function.

\subsection{Exclusion Criteria}

The following exclusion criteria were used: (i) reviews, (ii) clinical articles, (iii) book chapters, (iv) protocols, (v) editorials/expert opinions, (vi) letters/communications, (vii) publications in languages other than English, (viii) indexed articles published in more than one database (duplicates), and (ix) articles that did not analyze fibroblastic reticular cells' impact on $\mathrm{T}$ cell function.

\subsection{Data Extraction, Data Collection, and Risk of Bias Assessment}

In this review, all six authors (B.O.F.; F.A.O.; M.P.N.; G.N.A.R.; L.F.G.; and L.C.M.), independently and in pairs, randomly selected, revised, and evaluated the titles and abstracts of the publications identified by the search strategy in the databases cited above, and all the potentially relevant publications were retrieved in full. These same reviewers evaluated the full-text articles to decide whether the eligibility criteria were met. Discrepancies in the study selection and data extraction between the two reviewers were discussed with a third reviewer and resolved.

B.O.F. and F.A.O. searched for the characteristics of the hosts and interventions that they received before in vitro analysis; M.P.N. and G.N.A.R. searched for the characteristics of fibroblastic reticular cell isolation and immunophenotypic labeling; M.P.N. and F.A.O. searched for the characteristics of the main type of immune cells used for analysis with fibroblastic reticular cells; B.O.F. and G.N.A.R. searched for the main characteristics of the studies used to assess the influence of fibroblastic reticular cells on the activation, expansion, or suppression of immune responses. The analysis process and table plots were carried out by the full consensus of peers, respecting the distribution above. In cases of disagreement, two senior researchers, L.F.G. and L.C.M., decided to add or subtract data. The final inclusion of the studies into the systematic review was by agreement of all reviewers.

\subsection{Data Analysis}

All the results are described and presented using the percentage distribution for all variables analyzed in the tables.

\section{Results}

\subsection{Selection Process of the Articles Identified According to the PRISMA Guidelines}

We searched for articles indexed in the Pubmed, Scopus, and Cochrane libraries published between 2016 and 2020, and a total of 175 articles were identified in these databases. Of the 32 articles identified in Pubmed, 4 were excluded because they were reviews. After the Pubmed screening, 11 articles were not included due to the lack of analysis on FRCs' impact on T cell function, and 17 full-text articles were assessed for eligibility. Of the 43 articles identified in Scopus, 17 were duplicated in the Pubmed database, with 26 records remaining for screening, of which 19 articles were not included due to the lack of analysis on FRCs' impact on T cell function. A total of 7 articles from the Scopus database were assessed for eligibility. From the Cochrane database, no articles identified in the search were included in this review due to not meeting the inclusion criteria. A total of 24 studies [18-41] were included in this review and the decision stages are summarized in Figure 1. 


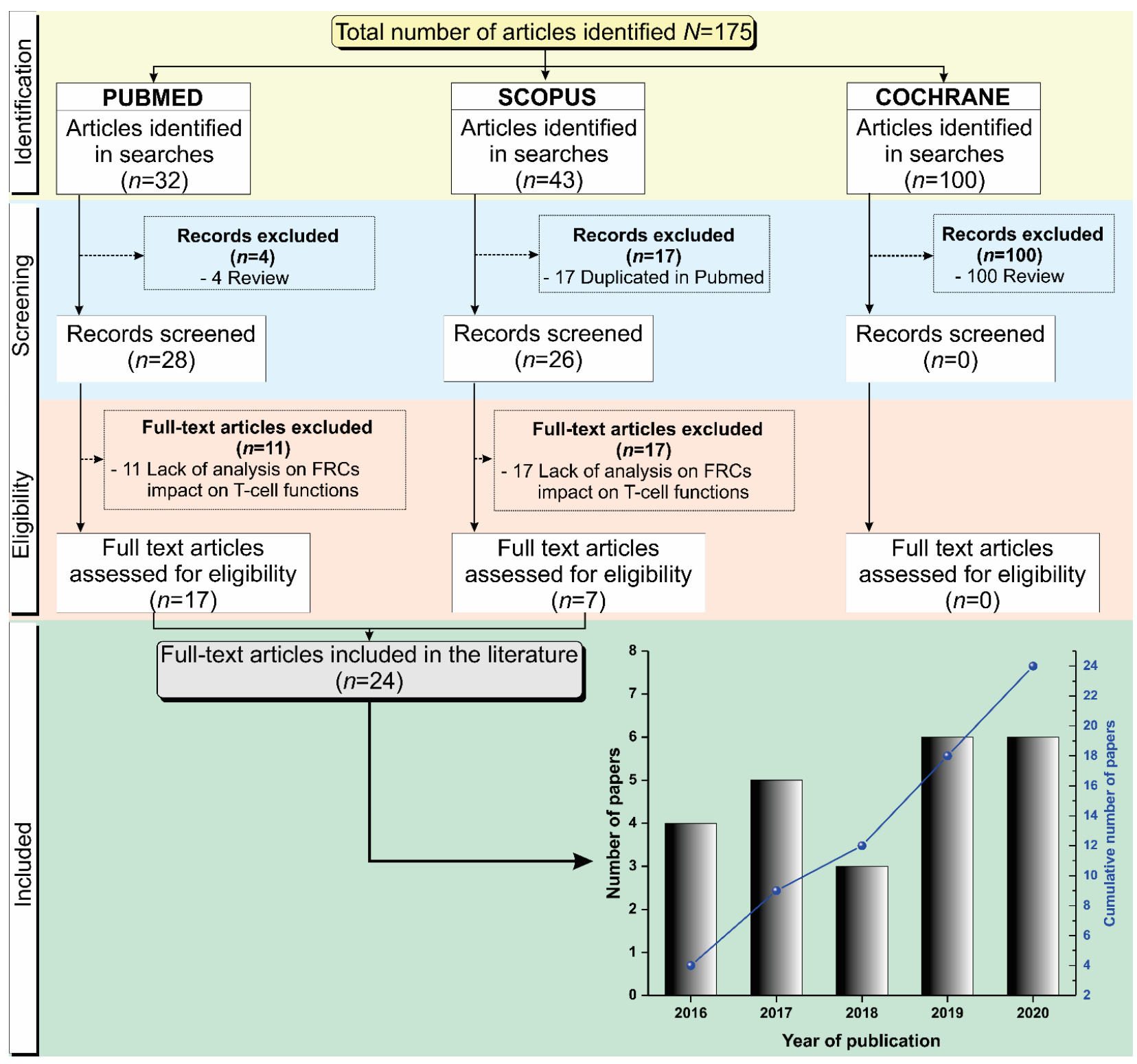

Figure 1. Schematic representation of the article screening process for their inclusion in this systematic review following the PRISMA guidelines. The histogram on the temporal distribution of the 24 articles included in this systematic review, by year of publication.

\subsection{Characteristics of the Host Used in the Studies Analyzing Fibroblastic Reticular Cell Function}

The host characteristics in the articles included in this review, such as source, genotype, age, and gender, are described in Table 1, along with the types and times of interventions used to analyze fibroblastic reticular cell functions. The hosts used in the majority of the studies reviewed here were C57BL/6 mice (79\%) [18,19,22-30,32-34,37-41]. There were 10 studies $(53 \%)$ that used some type of genetically modified mice $[21,22,25,28,30,32,33,35,38,40]$, of which $40 \%$ were NOD scid gamma (NSG) mice $[21,25,33,35]$ and $60 \%$ were RAG deficient mice [22,28,30,32,33,35]. 
Table 1. Characteristics of hosts and the interventions that they received before in vitro analysis.

\begin{tabular}{|c|c|c|c|c|c|c|c|}
\hline \multirow{2}{*}{ Ref. } & \multirow{2}{*}{ Year } & \multicolumn{4}{|c|}{ Host } & \multicolumn{2}{|l|}{ Interventions } \\
\hline & & Source & Genotype & Age (Weeks) & Gender & Type & Time (Days) \\
\hline $\begin{array}{l}\text { Aparicio-Domingo } \\
\text { et al. [18] }\end{array}$ & 2020 & Mice C57BL/6J & IL-33gfp/gfp; IL-33gfp/+ & 7-19 & M & $\begin{array}{l}\text { LCMV clone } 13 \text { and WE virus; } \\
\text { tamoxifen }\end{array}$ & $\begin{array}{l}\text { Single dose; } \\
6 \text { (3/week) }\end{array}$ \\
\hline Dertschnig et al. [19] & 2020 & Mice C57BL/ 6 & $\begin{array}{c}\text { Female to male bone marrow } \\
\text { transplant model (BMT), T } \\
\text { cell-depleted, plus transgenic } \\
\text { TCR-CD8 MataHari (Mh) }\end{array}$ & NR & M & $\begin{array}{l}\text { Dexamethasone; DT; Gy } \\
\text { irradiation }\end{array}$ & $3 ; 4$ \\
\hline Eom et al. [20] & 2020 & Human & Metastatic melanoma and surgery & NA & NA & NA & NA \\
\hline Gonzalez et al. [21] & 2020 & $\begin{array}{c}\text { Mice (NOD/ShiLtJ, NOR/LtJ, } \\
\text { and NOD.CgTg); Human }\end{array}$ & $\begin{array}{c}\text { Type } 1 \\
\text { diabetes }\end{array}$ & 12 & $\mathrm{~F}$ & NA & NA \\
\hline Knop et al. [22] & 2020 & $\begin{array}{c}\text { Mice C57BL/6N and } \\
\text { ROSA26RFP }\end{array}$ & $\begin{array}{l}\mathrm{IL}^{-}{ }^{-/-}{ }^{-}, \mathrm{PGK}-\mathrm{Cre}, \mathrm{FLPO}, \\
\mathrm{RAG}^{-/}-, \text {, Thy } 1.1+\mathrm{OT}-\mathrm{I}\end{array}$ & NR & NR & NA & NA \\
\hline $\begin{array}{l}\text { Perez-Shibayama } \\
\text { et al. [23] }\end{array}$ & 2020 & Mice C57BL/ 6 & CCL19-Cre IFNAR ${ }^{\mathrm{fl} / \mathrm{fl}}$ & $8-10$ & NR & LCMV Armstrong & NR \\
\hline Brown et al. [24] & 2019 & Mice C57BL/ 6 & $\mathrm{IL}_{-} 6^{-/-} ; \mathrm{NOS}^{-/-}$ & $5-12$ & M & $\begin{array}{c}\text { PR8-GP33-41, LCMV, } \\
\text { influenza, OT-1 T cells with } \\
\text { OVA }\end{array}$ & NR \\
\hline Kelch et al. [26] & 2019 & Mice C57BL/6J & NA & $9-22$ & $\mathrm{M}$ & NA & NA \\
\hline Majumder et al. [27] & 2019 & Mice C57BL/6 & 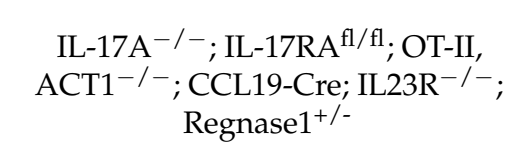 & $6-12$ & $\mathrm{M}-\mathrm{F}$ & $\begin{array}{c}\text { MOG with Mycobacterium } \\
\text { tuberculosis, pertussis toxin } \\
\text { on/OT-II CD4+ T cells with } \\
\text { OVA/DSS }\end{array}$ & 2 \\
\hline Masters et al. [28] & 2019 & Mice C57BL/6 & $\mathrm{RAG}^{-/-} ; \mathrm{CD} 45.1$ & $\begin{array}{l}2-4 \mathrm{~m} \text { and } \\
19-21 \mathrm{~m}\end{array}$ & $\mathrm{M}$ & Influenza & NR \\
\hline Schaeuble et al. [29] & 2019 & Mice C57BL/6 & $\begin{array}{c}\mathrm{NOS}^{-/-} ; \mathrm{OT}-1 ; \mathrm{COX}^{-/-} \\
\text {COX2 } \\
\text { ROSCL19Cre, and } \\
\text { ROS26-EYFPCCL19Cre }\end{array}$ & $\geq 6$ & NR & OVA and poly (I:C) & 4 \\
\hline Dubrot et al. [30] & 2018 & Mice C57BL/6 & $\begin{array}{l}\text { CIITA }^{-/-} ; \mathrm{pIV}^{-/-} ; \text {K14 TGP IVKO; } \\
\text { RAG2 }^{-/-} \text {PROX-1-Cre MHC-II }\end{array}$ & $>12 \mathrm{~m}$ & NR & Tamoxifen; IFN- $\gamma$ and FTY720 & $\begin{array}{c}4 \\
\text { (Twice/day); } \\
6\end{array}$ \\
\hline Knoblich et al. [31] & 2018 & Human & Cadaveric donors & NA & NA & NA & NA \\
\hline Maaraouf et al. [32] & 2018 & Mice C57BL/6 & CCL19-Cre; iDTR; RAG1 ${ }^{-/-}$ & NR & NR & DT; LT $\beta r-I g$ & $1 ; 2$ \\
\hline
\end{tabular}


Table 1. Cont

\begin{tabular}{|c|c|c|c|c|c|c|c|}
\hline \multirow{2}{*}{ Ref. } & \multirow{2}{*}{ Year } & \multicolumn{4}{|c|}{ Host } & \multicolumn{2}{|c|}{ Interventions } \\
\hline & & Source & Genotype & Age (Weeks) & Gender & Type & Time (Days) \\
\hline Chung et al. [33] & 2017 & Mice BALB/c or C57BL/ 6 & $\begin{array}{l}\text { TgMx1-Cre; DLL1 }{ }^{\mathrm{fl} / \mathrm{fl}} ; \mathrm{DLL}^{\mathrm{fl} / \mathrm{fl}} ; \\
\text { NOTCH2 } 2^{\mathrm{fl} / \mathrm{fl}} ; \mathrm{RAG}^{-/-}\end{array}$ & $6-10$ or $8-12$ & $\mathrm{M}-\mathrm{F}$ & $\begin{array}{c}\text { poly (I:C)/8.5-9 Gy; } \\
\text { poly (I:C)/6 Gy irradiation }\end{array}$ & $0.16 ; 0.12$ \\
\hline Gao et al. [34] & 2017 & Mice C57BL/ 6 and Human & Colon cancer & 6 & $\mathrm{~F}$ & Lewis Long carcinoma cells & NA \\
\hline Pazstoi et al. [35] & 2017 & Mice BALB/c & FOXP3hCD2xRAG2 ${ }^{-/-}$xD011.10 & NR & M-F & NA & NA \\
\hline Valencia et al. [36] & 2017 & Human & Brain-dead organ donors & NA & M-F & NA & NA \\
\hline Yu, M. et al. [37] & 2017 & Mice C57BL/ 6 and Human & $\begin{array}{l}\text { PTGS2 }{ }^{\mathrm{Y} 385 \mathrm{~F} / \mathrm{Y} 385 \mathrm{~F}} \text {; OVA-specific } \\
\text { CD8 (OT-I); CD4 (OT-II) }\end{array}$ & $4-6$ & NR & DC-vaccine & 1.5 \\
\hline Gil-Cruz et al. [38] & 2016 & $\begin{array}{c}\text { Mice C57BL/6N or } \\
\text { C57BL/6N-Tg or R26R-EYFP }\end{array}$ & Myd88-/-; TLR7 ${ }^{-/-} ;$CCL19-Cre & $8-10$ & NR & $\begin{array}{l}\text { MHV A59; Citrobacter } \\
\text { rodentium }\end{array}$ & $12 ; 6$ \\
\hline Novkovic et al. [39] & 2016 & $\begin{array}{l}\text { Mice C57BL/6N or } \\
\text { C57BL/6N-Tg }\end{array}$ & CCL19-Cre; iDTR & $6-9$ & NR & DT & 3 and 5 \\
\hline Royer et al. [40] & 2016 & Mice C57BL/ 6 or Gbt-1.1 & $\begin{array}{l}\text { CXCL10 }^{-/-} ; \mathrm{CXCR3}^{-/-} \\
\text {STING }^{-/-} ; \mathrm{CD}^{-/-} 8^{-/}\end{array}$ & $6-12$ & M-F & HSV-1 & NR \\
\hline Takeda et al. [41] & 2016 & Mice C57BL/6J & $\begin{array}{l}\text { LPAR2 }^{-/-} ; \text {ENPP2-flox, } \\
\text { CCCL19-Cre, LPAR5 }{ }^{-/-} \\
\text {' } \\
\text { LPAR6 } 6^{-/-}\end{array}$ & $8-12$ & NR & $\begin{array}{l}\text { CD4+ T cells labeled with } \\
\text { CMTMR; LT } \beta R-F c\end{array}$ & $0.6 ; 1.04 ; 28$ \\
\hline
\end{tabular}


Of these studies, $3[21,34,37]$ reported the use of mice and humans as the target hosts, and 3 studies used only humans $(13 \%)[20,31,36]$. Besides that, 4 studies $(19 \%)$ used the genetic background of C57BL/6J mice [18,25,26,41], 3 (13\%) used C57BL/6N [22,38,39], 2 used BALB/c2 [33,35] and C57BL/6N-Tg [38,39] (10\% each). The background of NOD/ ShiLtJ [21], NOR/LtJ [21], NOD.CgTg [21], ROSA26RFP [22], CD-1 IGS [25], R26R-EYFP [38], and Gbt-1.1 [40] mice were used in just 1 study each (5\%). Regarding genotypes, 4 studies (19\%) used knock-out or conditional knock-out mice for the cytokines IL-33 [18], IL-6 [24], IL-7 [22], and IL-17A [27]; 8 studies (38\%) used knock-out or conditional knock-out mice for chemokines or reporters for CCL19 [23,25,32,38-41], and CXCL10 [40]. A total of 5 studies (24\%) used knock-out or conditional knock-out mice for receptors such as IFN- $\alpha \mathrm{R}$ [23], IL-23R, IL-17AR [27], TLR7 [38], CXCR3 [40], and the lysophosphatidic acid (LPA) receptors LPAR, LPAR5, and LAPR6 [41]. In addition, 5 studies also used knock-out or conditional knock-out mice for the RAG enzyme $[27,28,30,33,35]$. Additionally, 7 studies $(33 \%)$ used knock-out or conditional knock-out mice for NOS [24,29], COX [29], MHC-II and its transcription factor CIITA [30], NOTCH2 and its Delta receptors DLL1 and DLL4 [33], and for the signaling molecules, such as ACT1 [27], MyD88 [38], and STING [40]. Finally, 3 studies $(14 \%)$ used mice with specific OVA-T cell receptors [22,29,37].

The mice age range was mainly from 5 to 22 days $[18,21,23-27,29,33,34,37-41]$, with the exception of the studies of Masters [28] and Dubrot [30], which used aged mice (older than 12 months). The animals' genders were reported in only $54 \%$ of the studies, of which $46 \%$ used only males [18,19,24-26,28], $15 \%$ used only females [21,34], and $39 \%$ used both $[27,33,35,36,40]$. Around $71 \%$ of the studies [18,19,23-25,27-30,32-34,37-41] used some type of host intervention, such as a diphtheria toxin $[19,25,32,39]$ or infection, using different types of virus or bacteria (LCMV [18,23,24], WE [18], PR8-GP33-41 [24], influenza [24,28], HSV-1 [40], mouse hepatitis virus A59, and Citrobacter rodentium [38]), or strategies that simulate viral infection, such as poly (I:C) [29,33], associated with irradiation or only irradiation [19], as well as immunization with OT-1 T cells with OVA [24,27], the use of drugs such as tamoxifen [18,30], or immunosupressors such as FTY720 [30], among others, with varied times of application.

\subsection{General Immunophenotypic Characteristics of Fibroblastic Reticular Cells}

The main characteristics of FRCs, lymph node (LN) digestion processes, and techniques used for their isolation are described in Table 2.

\subsubsection{Lymph Node Characteristics}

Among the 24 studies selected for this review, 12 (50\%) used FRCs derived from peripheral LNs (axillary, skin-draining, cervical, inguinal, popliteal, kidney, mandibular, mediastinum, pancreatic) $[18,21,23,25,29,30,32-34,37,39,40], 7$ (29\%) used a combination of peripheral and mesenteric LNs $[19,20,22,26-28,41], 3(13 \%)$ studies used only mesenteric LNs [35,36,38], and 2 studies did not disclose the LN source [24,31].

\subsubsection{Tissue Disaggregation Type}

Regarding the type of tissue disaggregation used in the studies, most of them $(83 \%)$ describe enzymatic digestion [18-24,27-29,31-35,37-39], 2 studies (8\%) performed mechanical tissue disruption [36,40], and another 2 used models of topological analyses [25,26], all described in Table 2. For the enzymatic digestion process, $38 \%$ of the studies used a combination of solutions, including Collagenase P, Dispase (I or II) and DNase I, [21,22,24,31,32,35,37,40,41]. In addition to the previous solution, the study of Knop et al. used Latrunculin B [22]. Another 8 studies (33\%) used only a combination of Collagenase (IV, D, F, or P) and DNase I $[23,29,30,33,34,38,39]$, and the study of Aparicio-Domingo et al. included $\mathrm{CaCl} 2$ in the final solution [18]. The work of Dertschnig and Eom used DNase, Liberase and DNase I, or Liberase $\mathrm{DH}$, respectively $[19,20]$. Masters et al. were the only ones to use the combination of Liberase TL and Benzonuclease [28]. 
Table 2. Characteristics of fibroblastic reticular cells isolation and their immunophenotype.

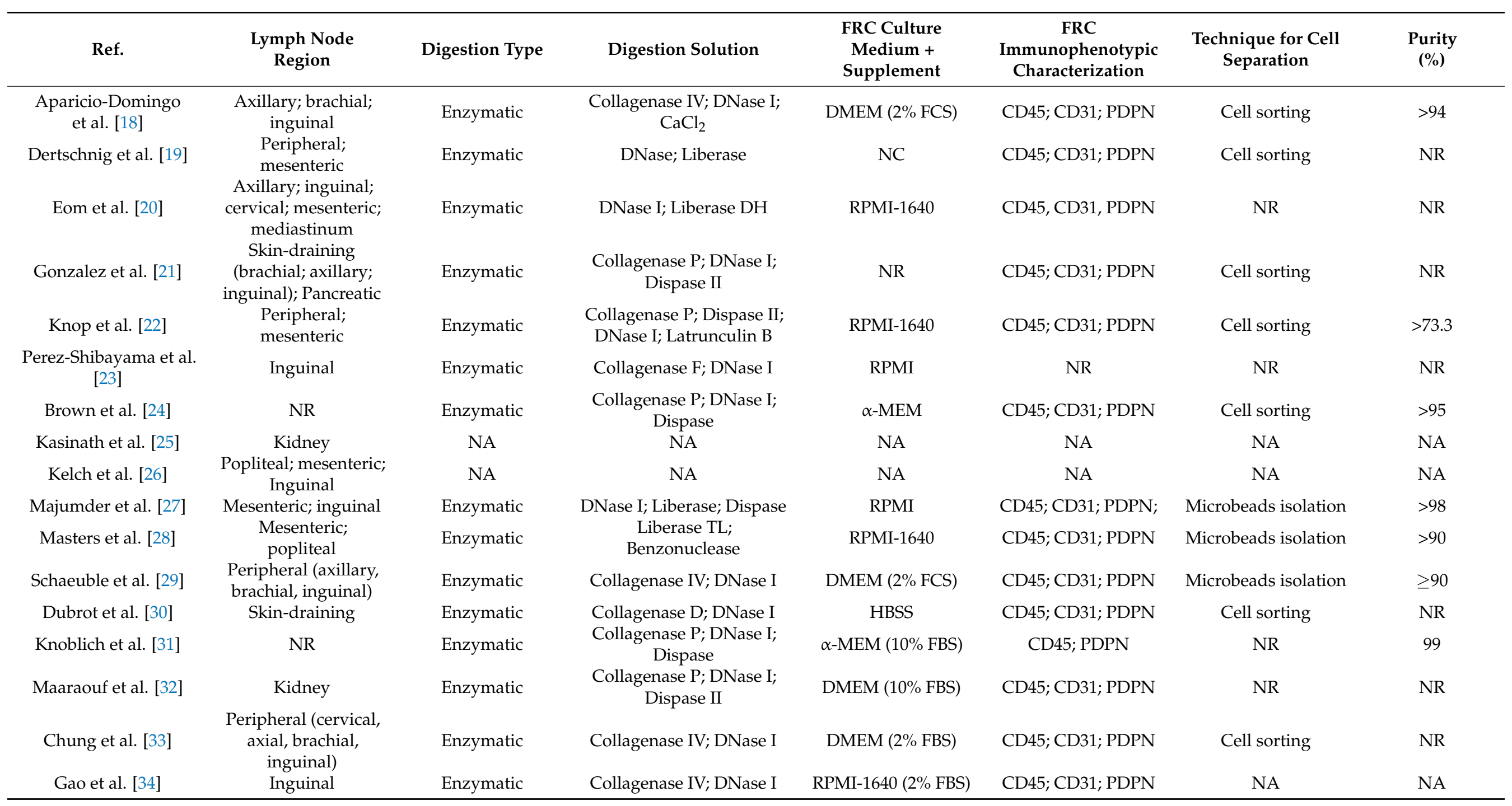


Table 2. Cont

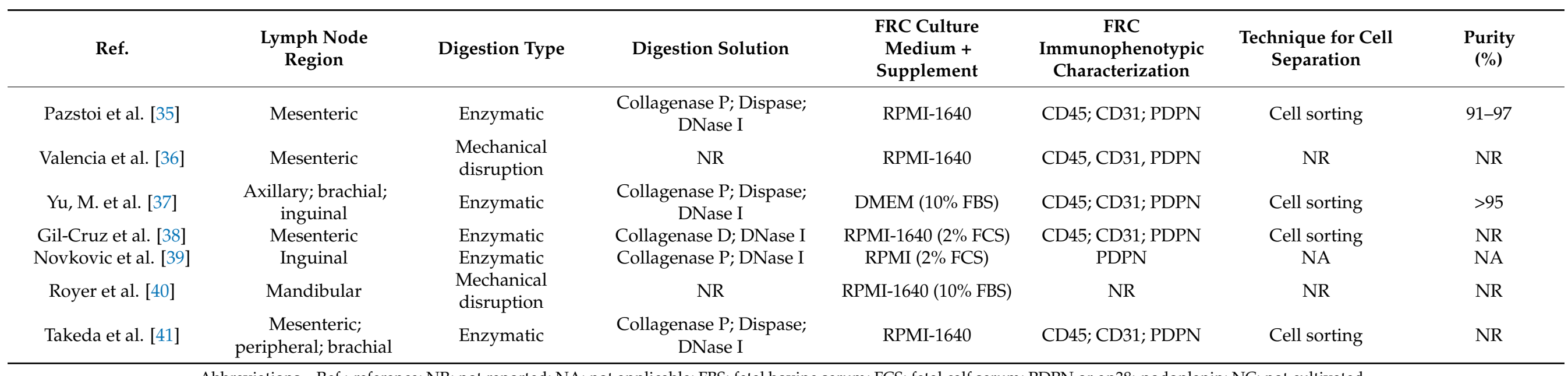

Abbreviations—Ref.: reference; NR: not reported; NA: not applicable; FBS: fetal bovine serum; FCS: fetal calf serum; PDPN or gp38: podoplanin; NC: not cultivated.

Table 3. Characteristics of the main type of immune cells used for analysis with fibroblastic reticular cells.

\begin{tabular}{|c|c|c|c|c|c|}
\hline Ref. & Source of Cells & Cell Type & Separation Technique & $\begin{array}{l}\text { Immune Cell } \\
\text { Preservation Solution } \\
\text { and Supplementation }\end{array}$ & $\begin{array}{l}\text { Immune Cell Immunophenotypic } \\
\text { Characterization }\end{array}$ \\
\hline Aparicio-Domingo et al. [18] & $\mathrm{LN}$ & CD8+ T cells & $\begin{array}{l}\text { Non selection performed } \\
\text { CD3 negative selection followed }\end{array}$ & DMEM ( $2 \%$ FCS $)$ & $\mathrm{CD} 45, \mathrm{CD} 8 \alpha, \mathrm{CD} 4, \mathrm{TRC} \alpha \beta$ \\
\hline Dertschnig et al. [19] & $\mathrm{LN}$ & $\mathrm{T}$ cells & $\begin{array}{c}\text { by } \\
\text { CD4 and CD8 } \alpha \\
\text { positive selection } \\
\text { (MicroBeads-Myltenyi) }\end{array}$ & NR & $\begin{array}{c}\mathrm{CD} 45, \mathrm{CD} 45.1, \mathrm{CD} 3, \mathrm{CD} 4, \mathrm{CD} 8 \alpha, \\
\text { CD62L, CD } 44, \mathrm{CD} 69, \mathrm{CD} 127, \mathrm{~V} \alpha 2, \mathrm{~V} \beta 5\end{array}$ \\
\hline Gonzalez et al. [21] & Spleen & CD8+ T cells & $\begin{array}{l}\text { CD8 isolation by negative } \\
\text { selection } \\
\text { (Microbeads-MojoSort) }\end{array}$ & NR & $\mathrm{CD} 45, \mathrm{CD} 8, \mathrm{CD} 44, \mathrm{CD} 25$ \\
\hline Knop et al. [22] & LN; spleen & $\mathrm{T}$ cells and NK & $\begin{array}{l}\text { CD8 } \alpha \text { positive selection } \\
\text { (MicroBeads-Myltenyi) }\end{array}$ & RPMI & $\begin{array}{c}\text { CD45, CD3, CD4, CD5, CD8 } \alpha, \text { CD62L, } \\
\text { Bcl-2, CD127, Nk1.1, ROR } \gamma \mathrm{t}\end{array}$ \\
\hline
\end{tabular}


Table 3. Cont.

\begin{tabular}{|c|c|c|c|c|c|}
\hline Ref. & Source of Cells & Cell Type & Separation Technique & $\begin{array}{l}\text { Immune Cell } \\
\text { Preservation Solution } \\
\text { and Supplementation }\end{array}$ & $\begin{array}{l}\text { Immune Cell Immunophenotypic } \\
\text { Characterization }\end{array}$ \\
\hline Perez-Shibayama et al. [23] & LN; spleen & $\begin{array}{c}\text { T cell subsets and } \\
\text { exhaustion }\end{array}$ & No selection performed & RPMI & $\begin{array}{l}\text { CD 45.1, CD 45.2, CD45R, CD } 8 \alpha, C D 8 \beta, \\
\text { CD3e, CD44 CD62L, PD-1, PDL1 }\end{array}$ \\
\hline Brown et al. [24] & LN & CD8+ T cells & $\begin{array}{l}\text { CD8 } \alpha \text { positive selection } \\
\text { (MicroBeads-Myltenyi) }\end{array}$ & RPMI; $\alpha$-MEM & $\begin{array}{c}\text { CD45.1, CD 45.2, CD3, CD4, CD8, } \\
\text { CD275, CD28, CD44 }\end{array}$ \\
\hline Kasinath et al. [25] & LN; spleen & CD4+ T cells & No selection performed & NR & $\begin{array}{c}\text { CD45, CD3, CD4, CD44, CD62L, } \\
\text { IL-17A }\end{array}$ \\
\hline Majumder et al. [27] & $\mathrm{LN}$ & $\mathrm{T}$ and $\mathrm{B}$ cells & $\mathrm{NR}$ & NR & $\begin{array}{l}\text { CD45, CD45.2, CD4, B220, IL-17A, } \\
\text { IL-17R }\end{array}$ \\
\hline Masters et al. [28] & LN; peripheral blood & $\mathrm{CD} 8+\mathrm{T}$ & $\begin{array}{l}\text { CD8 isolation by negative } \\
\text { selection } \\
\text { (Microbeads-MojoSort) }\end{array}$ & NR & CD45, CD45.1, CD45.2, CD69, CD8 $\alpha$ \\
\hline Schaeuble et al. [29] & LN; spleen & $\mathrm{T}$ cells & No selection performed & RPMI & $\begin{array}{c}\text { CD45, CD3, CD4, CD8 } \alpha, \text { CD44, CD62L, } \\
\text { CD279, FoxP3, CD25 }\end{array}$ \\
\hline Dubrot et al. [30] & LN; spleen & $\begin{array}{l}\text { T cells, B cells, Treg, and } \\
\text { DC }\end{array}$ & $\begin{array}{l}\text { Pan T isolation by negative } \\
\text { selection } \\
\text { (MicroBeads-Myltenyi) }\end{array}$ & NR & $\begin{array}{l}\text { CD45, CD44, CD3, CD4, CD8 } \alpha, \text { FOXp3, } \\
\text { Ly5.1, CD11b, CD19, CD25, CD62L, } \\
\text { PDCA-1, PD-1, IL-17, IFN } \gamma \mathrm{R}\end{array}$ \\
\hline Knoblich et al. [31] & LN; tonsils & $\mathrm{T}$ cells & $\begin{array}{l}\text { Pan T isolation by negative } \\
\text { selection } \\
\text { (MicroBeads-Myltenyi) }\end{array}$ & NR & $\begin{array}{c}\text { CD45, CD3, CD4, CD8, CD62L, CD27, } \\
\text { CD45RO, CD25 }\end{array}$ \\
\hline Maaraouf et al. [32] & Spleen & $\mathrm{T}$ cells & $\begin{array}{l}\text { Pan } \mathrm{T} \text { isolation by negative } \\
\text { selection } \\
\text { (MicroBeads-Myltenyi) }\end{array}$ & NR & $\mathrm{CD} 45, \mathrm{CD} 4$ \\
\hline Chung et al. [33] & $\begin{array}{l}\text { Spleen; peripheral } \\
\text { blood }\end{array}$ & $\begin{array}{l}\text { T cells, B cells, FDCs, Treg, } \\
\text { and DCs }\end{array}$ & $\begin{array}{l}\text { T cell Thy. } 1 \text { selection } \\
\text { (Microbeads-StemCells } \\
\text { Technologies) }\end{array}$ & NA & $\begin{array}{c}\text { CD45, CD3, CD4, CD8, FOXp3, CD157, } \\
\text { CD19, B220, CD44, CD62L, CD11c, } \\
\text { CD11b, CD169, CD21/35, F4/80, } \\
\text { TCR } \beta\end{array}$ \\
\hline Gao et al. [34] & $\mathrm{LN}$ & $\mathrm{T}$ cells & NR & NR & $\mathrm{CD} 45, \mathrm{CD} 4, \mathrm{CD} 8$ \\
\hline Pazstoi et al. [35] & $\mathrm{LN}$ & $\mathrm{T}$ cells & $\begin{array}{l}\text { CD4 positive selection } \\
\text { (Microbeads-Myltenyi) }\end{array}$ & EX VIVO & $\begin{array}{c}\mathrm{CD} 45, \mathrm{CD} 45.2, \mathrm{CD} 4, \mathrm{CD} 2, \mathrm{CD} 9, \mathrm{CD} 24, \\
\text { CD25, CD } 63\end{array}$ \\
\hline Valencia et al. [36] & $\mathrm{LN}$ & CD4+ T cells & $\begin{array}{c}\text { CD4 naïve T cell negative } \\
\text { selection } \\
\text { (Microbeads-Myltenyi) }\end{array}$ & RPMI (10\% FCS) & CD45, CD44, CD4 \\
\hline
\end{tabular}


Table 3. Cont.

\begin{tabular}{|c|c|c|c|c|c|}
\hline Ref. & Source of Cells & Cell Type & Separation Technique & $\begin{array}{l}\text { Immune Cell } \\
\text { Preservation Solution } \\
\text { and Supplementation }\end{array}$ & $\begin{array}{l}\text { Immune Cell Immunophenotypic } \\
\text { Characterization }\end{array}$ \\
\hline Yu, M. et al. [37] & $\mathrm{LN}$ & T cells & $\begin{array}{l}\text { Pan T cell negative selection } \\
\text { (Microbeads-StemCells } \\
\text { Technologies) }\end{array}$ & RPMI (10\% FBS) & $\begin{array}{l}\text { CD } 45, \text { CD } 45.1, \text { CD } 45.2, \text { CD } 3, \text { CD } 4, \\
\text { CD } 2 \alpha, \text { CD25, CD } 69, \text { CD } 44\end{array}$ \\
\hline Gil-Cruz et al. [38] & PP; LN & $\begin{array}{l}\text { T cells, B cells, NK cells, } \\
\text { Treg, and ILCs }\end{array}$ & 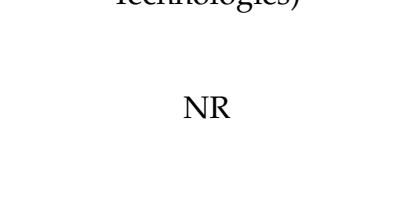 & RPMI (10\% FCS) & $\begin{array}{c}\text { CD45, CD3e, CD4, CD8 } \alpha, \text { EOMES, } \\
\text { FoxP3, B220, CD19, CD127, CD62L, } \\
\text { CD44, CD69, F4 /80, IL-17A, IL-7R } \alpha, \\
\text { GATA3, ROR } \gamma t \text {, IL-15R } \alpha \text { IL-15R } \beta, \\
\text { NKp46, NK1.1 }\end{array}$ \\
\hline Novkovic et al. [39] & LN; Spleen & DCs and T cells & $\mathrm{NR}$ & RPMI (2\% FCS) & CD45, CD3, CD8, CD4, CD11c, MHCII \\
\hline Royer et al. [40] & SLOs & CD8+ T cells & $\begin{array}{l}\text { CD8 positive selection } \\
\text { (Microbeads-Myltenyi) }\end{array}$ & RPMI (10\% FBS) & $\mathrm{CD} 45, \mathrm{CD} 3, \mathrm{CD} 4, \mathrm{CD} 8$ \\
\hline Takeda et al. [41] & LN; Spleen & $\mathrm{T}$ cells, $\mathrm{B}$ cells & $\begin{array}{l}\text { CD4 naïve T cell negative } \\
\text { selection } \\
\text { (Microbeads-Myltenyi) }\end{array}$ & RPMI & CD4, CD8, B220, CD44 \\
\hline
\end{tabular}

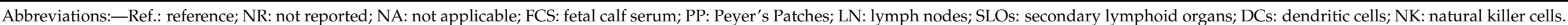

Table 4. Main characteristics of the studies used to assess the influence of fibroblastic reticular cells on the activation, expansion, or suppression of immune responses.

\begin{tabular}{|c|c|c|c|c|c|c|}
\hline Ref. & Trial Types & Study Target & $\begin{array}{c}\text { Time of } \\
\text { Intervention }\end{array}$ & $\begin{array}{l}\text { Main Performed } \\
\text { Evaluations }\end{array}$ & Results & $\begin{array}{c}\text { FRC Role in Immune } \\
\text { Response }\end{array}$ \\
\hline $\begin{array}{l}\text { Aparicio-Domingo et al. } \\
\text { [18] }\end{array}$ & IL-33-GFP reporter mice & LCMV & $\begin{array}{l}3 \text { days } / w \\
\text { for } 2 \text { weeks }\end{array}$ & $\begin{array}{l}\text { FC and RNA } \\
\text { sequencing }\end{array}$ & $\begin{array}{l}\text { FRC is one important IL-33 source in } \\
\text { LNs, vital for driving acute and } \\
\text { chronic antiviral T cell responses. }\end{array}$ & Anti-viral response \\
\hline Dertschnig et al. [19] & $\begin{array}{l}\text { FRC and DC ablation } \\
\text { in vivo; identification of PTA } \\
\text { regulatory genes; BTM } \\
\text { model induction }\end{array}$ & GvHD & 2 weeks & $\begin{array}{l}\text { FC, RNA sequencing, } \\
\text { confocal microscopy }\end{array}$ & $\begin{array}{c}\text { The loss of PTA presentation by FRCs } \\
\text { during GVHD leads to permanent } \\
\text { damage in their networks in } \\
\text { lymphoid tissues. }\end{array}$ & $\begin{array}{l}\text { Control of peripheral } \\
\text { tolerance }\end{array}$ \\
\hline
\end{tabular}


Table 4. Cont.

\begin{tabular}{|c|c|c|c|c|c|c|}
\hline Ref. & Trial Types & Study Target & $\begin{array}{c}\text { Time of } \\
\text { Intervention }\end{array}$ & $\begin{array}{l}\text { Main Performed } \\
\text { Evaluations }\end{array}$ & Results & $\begin{array}{l}\text { FRC Role in Immune } \\
\text { Response }\end{array}$ \\
\hline Eom et al. [20] & $\begin{array}{l}\text { Identification of distinctive } \\
\text { subpopulations of CD90+ } \\
\text { SCs present } \\
\text { in melanoma-infiltrated LNs }\end{array}$ & Melanoma & NA & FC, gene expression & $\begin{array}{l}\text { There are several distinct subsets of } \\
\text { FRCs present in melanoma-infiltrated } \\
\text { LNs. These FRCs may be related to } \\
\text { cancer metastasis invasion and } \\
\text { progression by avoiding T cells } \\
\text { through secreted factors. }\end{array}$ & $\begin{array}{l}\text { Lymph node invasion } \\
\text { metastasis and its } \\
\text { correlation with FRC } \\
\text { gene expression. }\end{array}$ \\
\hline Gonzalez et al. [21] & $\begin{array}{l}\text { Tissue-engineered stromal } \\
\text { reticula and FRC/T cell } \\
\text { co-culture }\end{array}$ & $\begin{array}{c}\text { Type } 1 \\
\text { diabetes }\end{array}$ & NA & $\begin{array}{c}\text { FC, } \\
\text { immunofluorescence, } \\
\text { imaging }\end{array}$ & $\begin{array}{l}\text { FRCs modulate their interactions with } \\
\text { autoreactive T cells by remodeling } \\
\text { their reticular network in LNs. FRC } \\
\text { with decreased contractility through } \\
\text { gp38 downregulation, can } \\
\text { loosen/relax their network, } \\
\text { potentially decreasing FRC } \\
\text { tolerogenic interactions with } \\
\text { autoreactive T cells and promoting } \\
\text { their escape from peripheral } \\
\text { regulation in LNs. }\end{array}$ & $\begin{array}{l}\text { Role of FRCs on } \\
\text { tolerance and T1D }\end{array}$ \\
\hline Knop et al. [22] & $\begin{array}{l}\mathrm{IL}-7^{\mathrm{fl} / \mathrm{fl}} \text { mice and adoptive } \mathrm{T} \\
\text { cell transfer }\end{array}$ & NA & NA & FC & $\begin{array}{c}\text { IL7, produced by LN FRCs-regulated } \\
\mathrm{T} \text { cell homeostasis, is crucial for } \mathrm{T}_{\mathrm{CM}} \\
\text { maintenance. }\end{array}$ & $\begin{array}{l}\text { IL7 produced by LN } \\
\text { FRCs is crucial for } \mathrm{T}_{\mathrm{CM}} \\
\text { maintenance }\end{array}$ \\
\hline $\begin{array}{l}\text { Perez-Shibayama et al. } \\
\text { [23] }\end{array}$ & $\begin{array}{l}\text { LCMV-infected mice, FRC ex } \\
\text { vivo restimulation and } \\
\text { cytokine production }\end{array}$ & $\begin{array}{c}\text { LCMV } \\
\text { Armstrong }\end{array}$ & $8 \mathrm{~d}$ & FC & $\begin{array}{c}\text { IFNAR-dependent shift of FRC } \\
\text { subsets toward an immunoregulatory } \\
\text { state reduces exhaustive CD8+ T cell } \\
\text { activation. }\end{array}$ & $\begin{array}{l}\text { IFN type } 1 \text { influences } \\
\text { FRC peripheral tolerance }\end{array}$ \\
\hline Brown et al. [24] & FRC/T cell co-cultures & $\begin{array}{l}\text { Influenza and } \\
\text { LCMV } \\
\text { infection }\end{array}$ & NR & $\begin{array}{l}\text { FC and RNA } \\
\text { sequencing }\end{array}$ & $\begin{array}{l}\text { FRCs play a role over restricting T cell } \\
\text { expansion-they can also outline the } \\
\text { fate and function of CD8+ T cells } \\
\text { through their IL-6 production. }\end{array}$ & $\begin{array}{c}\text { FRCs influence the CD8 } \\
\text { T cells fate }\end{array}$ \\
\hline
\end{tabular}


Table 4. Cont.

\begin{tabular}{|c|c|c|c|c|c|c|}
\hline Ref. & Trial Types & Study Target & $\begin{array}{c}\text { Time of } \\
\text { Intervention }\end{array}$ & $\begin{array}{l}\text { Main Performed } \\
\text { Evaluations }\end{array}$ & Results & $\begin{array}{l}\text { FRC Role in Immune } \\
\text { Response }\end{array}$ \\
\hline Kasinath et al. [25] & $\begin{array}{l}\text { Mouse FRC depletion and } \\
\text { treatment with anti-PDPN } \\
\text { antibody }\end{array}$ & $\begin{array}{l}\text { Crescentic } \\
\text { Glomeru- } \\
\text { lonephritis } \\
\text { (GN) }\end{array}$ & $3 d$ & $\begin{array}{l}\text { FC and gene } \\
\text { expression }\end{array}$ & $\begin{array}{l}\text { Removal of kidney-draining lymph } \\
\text { nodes, depletion of fibroblastic } \\
\text { reticular cells, and treatment with } \\
\text { anti-podoplanin antibodies each } \\
\text { resulted in the reduction of kidney } \\
\text { injury in GN. }\end{array}$ & $\begin{array}{l}\text { Role of FRCs and PDPN } \\
\text { expression in GN }\end{array}$ \\
\hline Kelch et al. [26] & $\begin{array}{l}\text { 3D imaging and topological } \\
\text { mapping }\end{array}$ & NA & NA & $\begin{array}{l}\text { EVIS imaging and } \\
\text { confocal microscopy }\end{array}$ & $\begin{array}{l}\text { T cell zones showed homogeneous } \\
\text { branching, conduit density was } \\
\text { significantly higher in the superficial } \\
\text { T cell zone compared with the deep } \\
\text { zone. Although the biological } \\
\text { significance of this structural } \\
\text { segregation is still unclear, } \\
\text { independent reports have pointed to } \\
\text { an asymmetry in cell positioning in } \\
\text { both zones. Naive T cells tend to } \\
\text { occupy the deep TCZ, whereas } \\
\text { memory T cells preferentially locate } \\
\text { to the superficial zones, } \\
\text { and innate effector cells can often be } \\
\text { found in the interfollicular regions. }\end{array}$ & $\begin{array}{l}\text { FRC conduits and their } \\
\text { distribution inside LNs }\end{array}$ \\
\hline Majumder et al. [27] & Metabolic assay & $\begin{array}{l}\text { Experimental } \\
\text { autoimmune } \\
\quad \text { en- } \\
\text { cephalomyeli- } \\
\quad \text { tis }\end{array}$ & $7 \mathrm{~d}$ & $\begin{array}{l}\text { FC, immunoblotting, } \\
\text { siRNA transfection }\end{array}$ & $\begin{array}{l}\text { During Th17 differentiation in LNs, } \\
\text { IL-17 signals to FRCs and impacts LN } \\
\text { stromal organization by promoting } \\
\text { FRC activation through a switch on } \\
\text { their phenotype from quiescence to } \\
\text { highly metabolic. }\end{array}$ & $\begin{array}{l}\text { FRCs are impacted by } \\
\text { metabolic alterations } \\
\text { driven by IL-17 }\end{array}$ \\
\hline Masters et al. [28] & $\begin{array}{l}\text { FRC-mediated T cell } \\
\text { proliferation inhibition and } \\
\text { T cell survival assays }\end{array}$ & $\begin{array}{l}\text { Aging and } \\
\text { influenza } \\
\text { infection }\end{array}$ & NR & FC & $\begin{array}{l}\text { Age-related changes in LN stromal } \\
\text { cells may have the largest impact on } \\
\text { the initiation of the immune response } \\
\text { to influenza infection, and may be a } \\
\text { factor contributing to delayed T cell } \\
\text { responses to this virus. }\end{array}$ & $\begin{array}{l}\text { Aging impacts the } \\
\text { adaptive anti-viral } \\
\text { immune response } \\
\text { initiation in LN }\end{array}$ \\
\hline
\end{tabular}


Table 4. Cont.

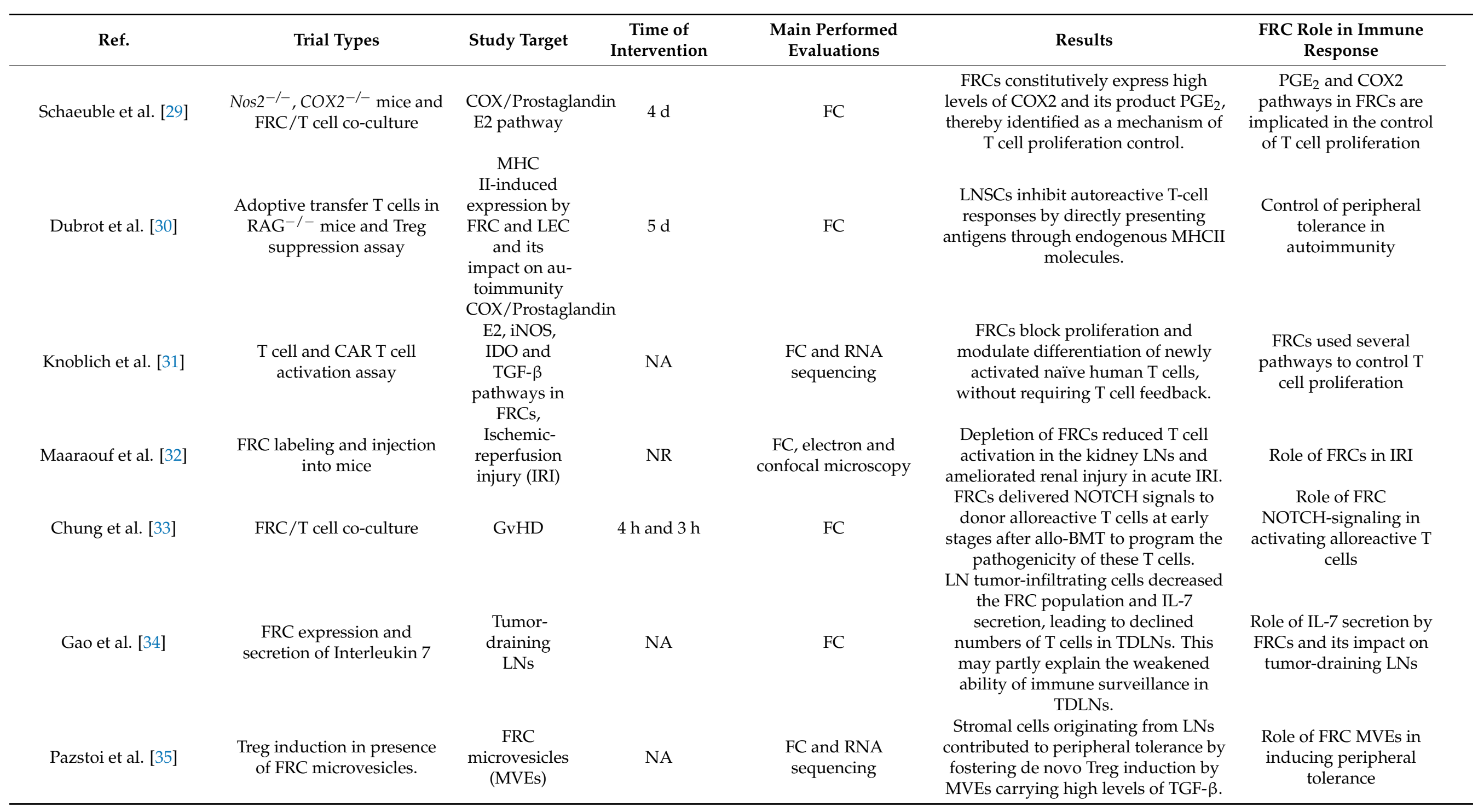


Table 4. Cont.

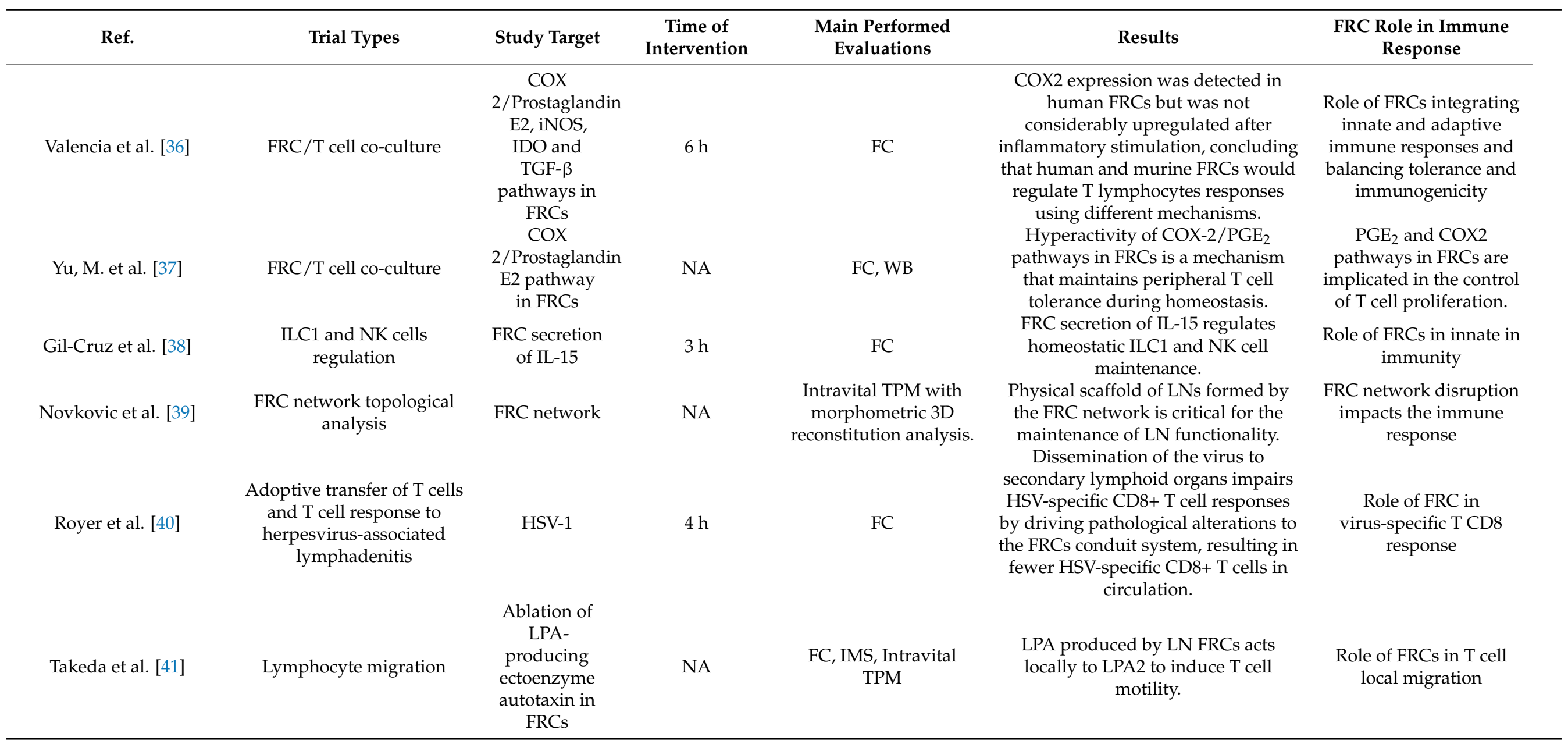

Abbreviations-Ref.: reference; NR: not reported; NA: not applicable; FC: flow cytometry; WB: Western blotting; IMS: imaging mass spectrometry; Intravital TPM: intravital two-photon microscopy. 


\subsubsection{Culture Media Details}

Of the culture media used for FRC cultivation, RPMI was the most popular medium and was used in $38 \%$ of the studies, even though there were differences in its supplementation. A total of 9 studies used 2 to $10 \%$ of fetal bovine serum (FBS) for supplementation $[20,22,28,34-36,38,40,41]$. In addition, 5 studies (21\%) used DMEM as a culture medium, supplemented with $2 \%$ of fetal calf serum (FCS) or 2 to $10 \%$ of FBS $[18,29,32,33,37]$. Another 2 studies mentioned the use of RPMI without supplementation [23,27], and Novkovic's study used RPMI supplemented with $2 \%$ of FCS [39]. Brown and Knoblich's studies used $\alpha$-MEM [24,31]; Dubrot, HBSS [30], Gonzalez did not disclose the culture medium used [21], and Dertschnig et al. did not cultivate the FRCs [19].

\subsubsection{FRC Characterization and Selection}

Most studies-18 of the 24 (75\%)—used the classical markers for FRC characterization, using antibodies to determine a population CD45-negative, CD31-negative, and podoplanin (PDPN or gp38)-positive [18-22,25,27-38]. Some studies (13\%) did not disclose the FRC characterization [23,40]; Knoblich et al. used CD45 and PDPN [31]. In regard to cell separation methods, the technique most used was cell sorting, using FACS (46\%) $[18,19,21,22,24,30,33,35,37,38,41]$, even though 6 studies did not report the used strategy $[20,23,31,32,36,40]$. Another 4 studies did not use cell sorting in their protocol $[25,26,35,38]$. In addition, 3 other studies used microbeads for cell separation [27-29]. Lastly, most studies $(46 \%)$ did not report the purity resulting from their cell selection $[19,21,23,30,32,33,36,38,40,41]$. Only 9 studies (38\%) reported a purity between $73-100 \%$ [18,22,24,27-29,31,35,37].

\subsection{Immunophenotypic Characteristics of Immune Cells Commonly Used in Studies with Fibroblastic Reticular Cells}

\subsubsection{Immune Cell Origins}

Secondary lymphoid organs (SLO) comprise a variety of immune cells and nonimmune cells; in the studies selected for this revision, the non-immune cells were FRCs. In this context, these studies verify the relation between FRCs and immune cells found in SLOs. Most studies used LNs (42\%) [18-20,24,26,27,34-37] or spleens (29\%) [22,23,25,29,30,39,41] as an immune cell source, $13 \%$ of the studies used, besides LNs, peripheral blood, tonsils, and Peyer's Patches cells [28,31,38]. Masters et al. [28] used peripheral blood cells in addition to LNs, Chung and Gonzalez used spleens instead of LNs [21,33], and Royer used several SLOs [40], all described in Table 3.

\subsubsection{Immune Cell Types}

The cells used in combination with FRCs in most studies (29\%) were total T lymphocytes $[19,29,31,32,34,35,37]$, followed by only T CD8 lymphocytes (20\%) $[18,21,24,28,40] ; 2$ studies $(8 \%)$ used T CD4 lymphocytes [25,36]; 2 studies ( $8 \%$ ) used a combination of T cells and $B$ cells [27,41]; 2 studies (8\%) did not evaluate the presence of immune cells [20,26]. Moreover, Knop et al. used T cells and NK cells [22]; Perez-Shibayama et al. used T cell subsets and exhaustion makers [23]; Dubrot et al. used a combination of T cells, B cells, Treg, and DCs [30]; Chung et al. used the same cells as Dubrot et al. but included FDCs in their study [33]; Gil-Cruz et al. used T cells, B cells, NK cells, Treg, and ILCs [38]; and Novkovic et al. used DCs and T cells [39], each study representing $4 \%$ of the total.

\subsubsection{Immune Cell Selection}

Regarding the separation techniques of immune cells, 4 studies (17\%) used Pan T isolation by negative selection [30-32,37], 4 studies did not perform selection $[18,23,25,29]$, and 4 studies did not report the separation technique [27,34,38,39]. Another 3 studies (13\%) used CD8 positive selection [22,24,40], 2 studies ( $8 \%$ ) used CD8 isolation by negative selection [21,28], 2 studies used CD4 naïve T cell negative selection [36,41], and for 2 other studies, this method was not applicable [20,26]. Dertschnig et al. used CD3 negative selection, followed by CD4 and CD8 $\alpha$ positive selection [19]; Chung et al. used T cell Thy.1 
selection [33]; and Pazstoi et al. used CD4 positive selection [35], each study representing $4 \%$ of the total.

\subsubsection{Immune Cell Culture}

In regards to the media used for immune cells, $38 \%$ of the studies used RPMI as the same medium used to culture the FRCS [22,23,29,36-41]. A total of 5 studies (21\%) used RPMI supplemented with $10 \%$ of FBS [22,23,37,40,41]. Another 4 studies used RPMI supplemented with $2 \%$ to $10 \%$ of FBS $[29,36,38,39]$. Aparicio-Domingo et al. used DMEM with $2 \%$ of FCS [18]; Brown et al. used both RPMI and $\alpha$-MEM [24], while Pazstoi used X-VIVO [35]. Another 9 studies (38\%) did not disclose the medium used [19,21,25,27,28,30-32,34].

\subsection{Studies Used to Assess the Influence of Fibroblastic Reticular Cells on Immune Response}

The studies used different strategies in order to access the contribution of FRCs to different mechanisms involved in the immune response (Table 4). A total of 5 studies $(21 \%)$ evaluated viral infection in this context: 2 of them used LCMV [18,23], 1 used influenza [24,28], 1 used HSV-1 [40], and 1 used both LCMV and influenza [18]. Another 4 studies $(17 \%)$ used inflammation as a model for targeting the COX:PGE 2 pathway $[29,31,36,37]$. Another 3 studies $(13 \%)$ used a model of autoimmunity, including Type 1 diabetes [21], glomerulonephritis [25], and experimental autoimmune encephalomyelitis (EAE) [27]. Another 2 studies (8\%) used a model for GvHD [19,33], 2 studies used cancer $(8 \%)$ as models of study -1 melanoma [20] and 1 tumor-draining lymph nodes [34]. One study (4\%) used a model of ischemic-reperfusion injury (IRI) [32]. Another 4 studies targeted just one particular pathway, such as MHC II expression [30], FRC microvesicles [35], FRC secretion of IL-15 [38], the FRC network [39], or the ablation of the LPA-producing ectoenzyme autotaxin in FRCs [41].

Most studies, $21(87 \%)$, used flow cytometry in order to separate and/or evaluate their cell populations and results $[18-25,27-38,40,41]$. Another 6 studies $(25 \%)$ used RNA sequencing or gene expression in order to have more broad information about their models $[18-20,24,25,31,35]$. A total of 4 studies $(16 \%)$ used, in addition to FC, intravital and/or confocal microscopy in order to complement their results [19,21,32,41]. In addition, 2 studies $(8 \%)$ were complemented with siRNA and Western blotting [27,37]. Moreover, 2 studies [ $8 \%$ ] only used intravital and/or confocal or electronic microscopy to evaluate their models $[26,39]$.

3.5.1. The Role of FRCs in the Immune Response Varied According to the Model Studied Anti-Viral Response

In studies related to the anti-viral response, Aparicio-Domingo et al., in an LCMV study, concluded that FRCs displayed a stimulatory role, being an important source of IL-33 in the lymph node and vital for driving acute and chronic antiviral $\mathrm{T}$ cell responses [18], while Perez-Shibayama et al., who also used LCMV as a model and found a regulatory role for FRCs, showed an IFN- $\alpha$-signaling dependent shift of FRCs toward an immunoregulatory state, reducing exhaustive CD8 T lymphocyte activation [23]. Yet, in an anti-viral response for influenza, Brown et al. [24] showed that FRCs have a role beyond a regulatory one in reducing $\mathrm{T}$ cell expansion-they also outline the fate and function of CD8 T lymphocytes through their IL-6 production. Moreover, Masters et al. reported that after aging-related changes, FRCs have their impact altered on the initiation of the immune response to influenza infection, and this contributes to delayed $\mathrm{T}$ lymphocytes responses to this virus [28]. Finally, Royer et al. proposed, in their study, that HSV-1-infected lymph nodes can cause pathological alterations in FRC conduit systems, resulting in fewer HSV-specific CD8 T lymphocytes in circulation, and a diminished anti-viral response to this virus [40]. 


\section{Inflammatory Response}

Regarding inflammation and the COX:PGE 2 pathway, Schaeuble et al. found that FRCs constitutively express high levels of COX2 and its product $\mathrm{PGE}_{2}$, thereby identified as a mechanism of $\mathrm{T}$ lymphocyte proliferation control [29] Knoblich et al. also demonstrated that FRCs control T cell proliferation and modulate their differentiation [31]. Yu, M. et al. also agree that a hyperactivated $\mathrm{COX}-2 / \mathrm{PGE}_{2}$ pathway in FRCs is a mechanism that maintains peripheral $\mathrm{T}$ cell tolerance [37]. Valencia et al. discussed the differences between mice and humans regarding COX inflammatory pathways, and concluded that human and murine FRCs would regulate T lymphocyte responses using different mechanisms, arguing that in humans, IDO would play a more important role than iNOS/NO [36].

\section{Autoimmunity}

Further, an autoimmunity FRC network seems to play an important role. Gonzalez et al., using a type 1 diabetes model, found that FRCs modulate their interactions with autoreactive T lymphocytes by remodeling their reticular network in LNs, and podoplanin plays a central role in this alteration [21]. Kasinath et al., using glomerulonephritis (GN), showed that the removal of a kidney-draining lymph node, the depletion of fibroblastic reticular cells, or treatment with anti-podoplanin antibodies all resulted in a reduction of kidney injury in GN [25]. Finally, Majumder et al., in EAE, showed that Th17 differentiation in LNs leads to IL-17 signaling to FRCs and an impact on LN stromal organization by promoting FRC activation through a switch on their phenotype from quiescence to highly metabolic [27].

\section{GvHD}

Moreover, in graft versus host disease (GvHD), FRCs' abilities for peripheral tissue antigen (PTA) presentation and NOTCH signaling have shown to be important features for the aggravation and maintenance of this state. Dertschnig et al. showed that the loss of PTA presentation by FRCs during GVHD leads to permanent damage in their networks in lymphoid tissues [19], and Chung et al. showed that FRC-delivered NOTCH signals to donor alloreactive $\mathrm{T}$ cells help to program the pathogenicity of these $\mathrm{T}$ cells [33].

\section{Metastatic Cancer}

In metastatic cancer, FRCs appear to be regulated by the tumor cells. Eom et al. showed in melanoma that FRCs in tumor-infiltrated LNs may favor cancer invasion and progression through the secretion of soluble factors [20], and Gao et al. also showed in tumor-infiltrated LNs a decrease in FRCs and IL-7 secretion, leading to a declined number of T lymphocytes in LNs [34].

Renal Injury

As seen by Kasinath et al. in GN [25], Maaraouf et al. using ischemic reperfusion injury (IRI) also confirmed that depletion of FRCs reduced T cell activation in the kidney LNs and ameliorated renal injury in acute IRI [32].

Specific Signaling Pathways

Regarding pathway investigation, Knop et al. described the essential role of IL7 derived from FRCs for central memory T cell survival [16]; Dubrot et al. showed a mechanism of T lymphocyte proliferation inhibition by the induced expression of MHC II [30]; Pazstoi et al. described that FRCs contribute to peripheral tolerance by fostering de novo Treg induction by MVEs carrying high levels of TGF- $\beta$ [35]; Gil-Cruz et al. commented on the role of FRCs on innate lymphocytes ILC1 and NK through IL-15 secretion [38]; Novkovic confirmed that the physical scaffold of LNs formed by the FRC network is critical for the maintenance and functionality of LNs [39]; Takeda et al. demonstrated the role of LPA derived from FRCs in T lymphocyte motility [41]. 


\section{Discussion}

FRC is a specific subset of stromal cells present in the lymph node, and they are precisely located in the $\mathrm{T}$ cell zone. There are other stromal cell subsets in lymph nodes, described as double-negative cells, follicular dendritic cells, blood endothelial cells, lymphatic endothelial cells, and others that are not discussed in this review [43].

The results of this review firstly show the characteristics of the host type used for analyzing FRC function. In addition, strategies used by them in order to achieve their target objectives, including model characteristics, such as source, genotype, age, and gender, are described in Table 1. The main characteristics of FRCs, their origin, as well the lymph node (LN) digestion process, and techniques used for their isolation are described in Table 2. The immune cell sources, as well as their characteristics, are described in Table 3. All these variations between the models studied, cell origins, and characterization, sometimes lead to different conclusions, making the comparison between studies difficult or conflicting, such as the role of FRCs in T cell proliferation, sometimes described as stimulators and, at other times, as limiting. Next, we assembled the studies with the same subject (Table 4) and compared them, trying to show the differences and, more importantly, comparisons between the achieved results (Figure 2).

The first scenario discussed was on viral infection (Figure 2A). Aparicio-Domingo et al., in an LCMV study, concluded that FRCs displayed a stimulatory role, being a main source of IL-33 in the lymph node and crucial for leading to acute and chronic antiviral T cell responses. They also showed that FRCs mainly act on CD8 T lymphocytes by signaling via ST2 expressed by these T cells [18]. Severino et al. demonstrated previously, in 2017, the increased IL-33 gene expression in human FRCs after treatment with IFN- $\gamma$ or IL-1 $\beta$ and TNF- $\alpha$. These cytokines are usually released during a course of an immune response, supporting the Aparicio-Domingo et al. findings that FRCs are the main source for IL-33 [9].

Perez-Shibayama et al., using the LCMV model like Aparicio-Domingo et al., commented that FRCs contributed to an immunostimulatory state to prevent virus replication and spread. However, they also found a regulatory role of FRCs, showing an IFN- $\alpha$ signaling dependent shift of FRCs toward an immunoregulatory state, reducing exhaustive CD8 T lymphocyte activation. They claim that type 1 IFN-mediated control of LCMV replication in FRCs is one of the major factors that determine the quality of the antiviral CD8+ T cell response [23]. In agreement, Talemi and Hofer sustain the idea that interferons delay the viral spread in infection, acting as sentinels, warning uninfected cells, and also are negative feedback regulators acting at a single-cell level [44].

Regarding the anti-viral response for influenza and LCMV, Brown et al. [24] showed that FRCs function is more than controlling $\mathrm{T}$ cell expansion. FRCs also outline the fate and function of CD8 T lymphocytes through their IL-6 production, and CD8 T cells exposed to both FCRs and IL-6 are driven to a memory phenotype. In addition, CD8 T cells cultivated in the presence of FRCs are more persistent during a viral infection than CD8 $\mathrm{T}$ cells stimulated without FRC presence [24]. Moreover, the pleiotropic function and the importance of IL- 6 were reported before, supporting that this cytokine, in certain environments, could be an important player for guiding the immune response [45]. Next, Masters et al., reported that after aging-related changes, FRCs have an altered impact on the beginning of the immune response to influenza infection, consequently contributing to delayed T lymphocytes responses to this virus [28]. Moreover, their findings on the importance of homeostatic chemokines for the success of the anti-viral response are also supported by Chai et al., who previously reported on the importance of these chemokines secreted by FRCs to the immune response against virus infection, and by Thompson et al., who also reported on the role of the lymph node in aging mice and its negative impact on T cells $[46,47]$. Lastly, Royer et al. proposed that HSV-1 in lymph nodes can cause pathological alterations in the FRC conduit system, resulting in fewer HSV-specific CD8 T lymphocytes in circulation, and a diminished anti-viral response to this virus. In addition, they claim that immunodeficiency can occur as a secondary outcome of FRC alterations to 
SLOs [40]. Their results are supported by other models that impair $\mathrm{T}$ cell responses due to virus-associated damage to FRCs [48,49].

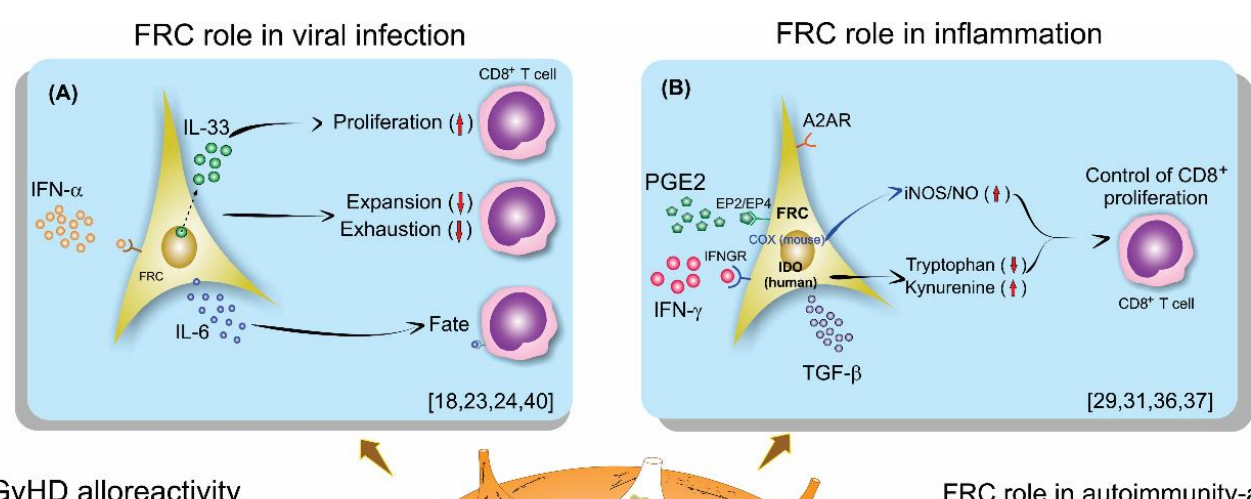

FRC role in GvHD alloreactivity
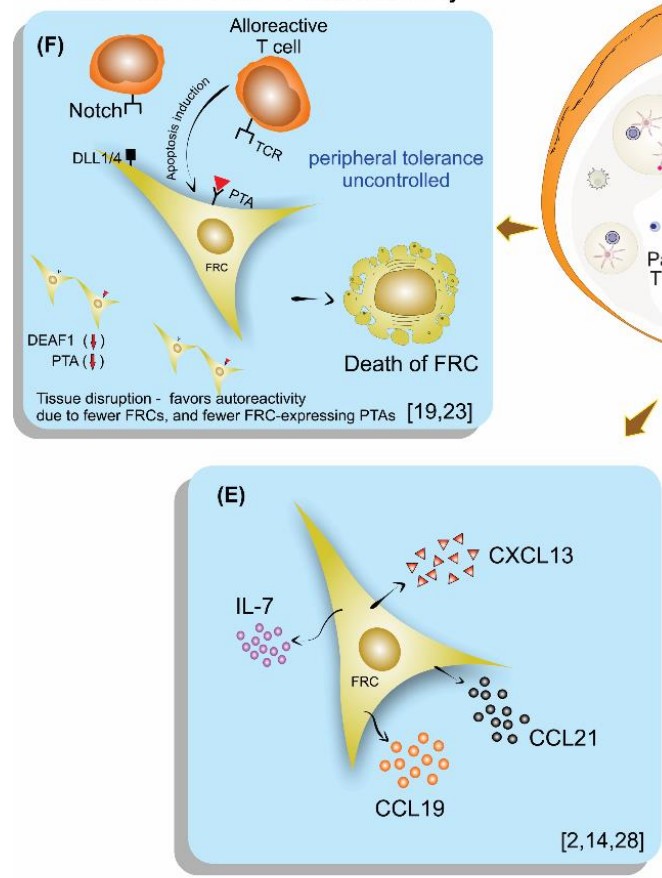

$\mathrm{FRC}$ role in homeostasis

\section{(14)}

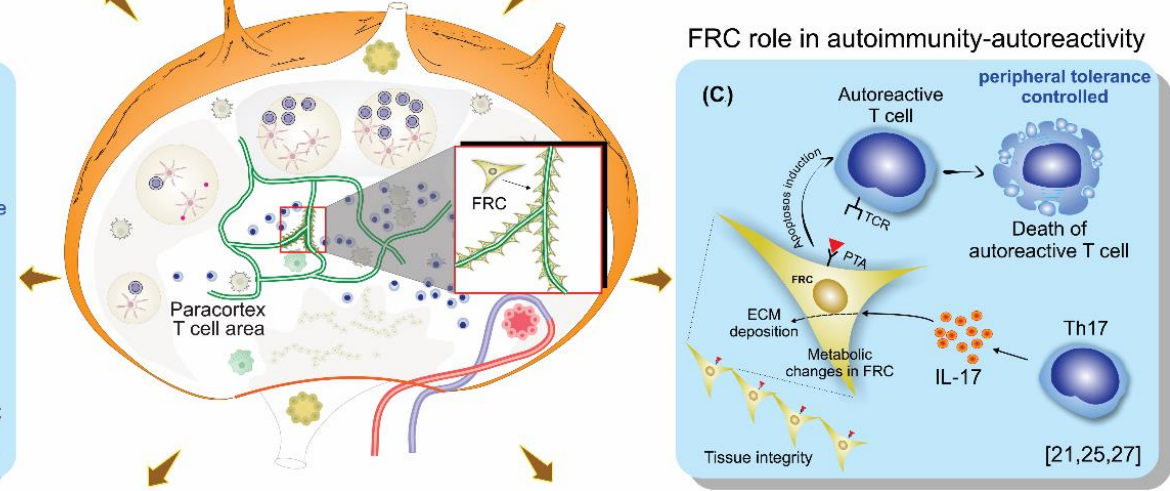

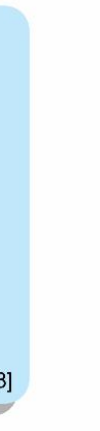

.

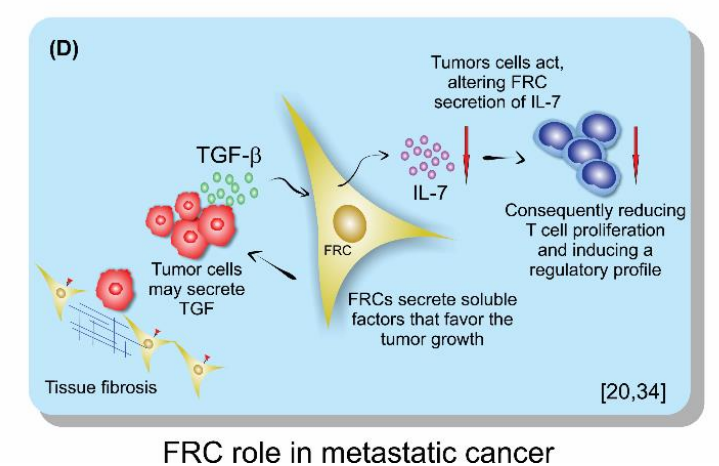

Figure 2. Schematic illustration of lymph nodes, FRC localization, and their role on lymphocytes in different scenarios of the immune response: (A) Viral infection, (B) Inflammation, (C) Autoimmunity, (D) Metastatic cancer, (E) Homeostasis, (F) GvHD.

Concerning inflammation (Figure $2 \mathrm{~B}$ ) and the $\mathrm{COX} / \mathrm{PGE}_{2}$ pathway, which converts arachidonic acid in several prostanoids via the enzymes COX1 and COX2, FRCs have been proposed to play dual roles by either promoting or inhibiting adaptive immunity [50,51], similar to myeloid and T cells. Schaeuble et al.'s experiments revealed that FRCs can control $\mathrm{T}$ cell responses, independently of other cells, by two pathways that lead to NO release, clarifying that one pathway is activated via the sensing of IFN-y by FRCs, which is activated only by strong $\mathrm{T}$ cell responses, and another pathway is mediated by COX2-dependent synthesis of $\mathrm{PGE}_{2}$, which signals via EP1 and EP2 during both weak and strong T cells responses [29]. Knoblich et al. also demonstrated that FRCs control $\mathrm{T}$ cell proliferation and modulate their differentiation [31]. Knoblich et al. included even more mechanisms that control T cell proliferation besides IFN-y and $\mathrm{PGE}_{2}$, which, in human cells, do not release $\mathrm{NO}$, but instead activate IDO; they point to TGF- $\beta$ and the adenosine $2 \mathrm{~A}$ receptor (A2AR) as other signaling pathways affecting $\mathrm{T}$ cell proliferation. They also demonstrated that human FRCs affect the fate of naïve $T$ cells, diminishing their differentiation into central memory while enhancing effector and effector memory phenotypes [31]. Yu, M. et al. support these 
findings with their previous study on the animal model and in vitro assays, confirming that hyperactive COX-2/ $\mathrm{PGE}_{2}$ pathways in FRCs are a mechanism that maintains peripheral $\mathrm{T}$ cell tolerance [37]. In addition, Valencia et al. demonstrated the differences between mice and humans regarding COX inflammatory pathways, and concluded that human and murine FRCs would regulate $\mathrm{T}$ lymphocytes responses using different mechanisms, and arguing that, in humans, IDO would play a more important role than iNOS/NO [36].

Further, in autoimmunity, the FRC network seems to play an important role (Figure 2C). Gonzalez et al., using a type 1 diabetes (T1D) model and a 3D system of culture, found that in T1D FRCs, the reticular network organization was altered, displayed larger pores, and had a lower expression of podoplanin compared to a control animal or control culture system. They also demonstrated a reduced expression of PTAs and T1D antigens in T1D FRCs. Consequently, FRCs modulated their interactions with autoreactive $\mathrm{T}$ lymphocytes by remodeling their reticular network in LNs; PTAs and podoplanin played a central role and their alterations may favor T1D [21]. These findings are supported by a previous study from the same group that investigated alterations in pancreatic lymph nodes from humans and mice [52]. Kasinath et al. studied crescentic glomerulonephritis (GN), an autoimmune inflammatory condition characterized by the rapid deterioration of kidney function. They investigated the role of fibroblastic reticular cells residing in the stromal compartment of the kidney lymph node in this model. They observed that FRCs are fundamental to the propagation of the immune response in nephrotoxic serum nephritis. Following GN development, they observed an increase in effector memory and Th17 cells in the kidney LN. In addition, they observed that the removal of the kidney lymph node, a depletion of fibroblastic reticular cells, and treatment with anti-podoplanin antibodies each resulted in a reduction of kidney injury [25]. Majumder et al. studied the EAE model, and they also showed Th17 differentiation in LNs and that the signaling in the receptor for IL-17 in FRCs is related to collagen deposition in LNs. This work suggests that Th17 cells promote ECM deposition in inflamed LNs through FRCs-IL-17 signaling, independently of LN size or hypercellularity. As a consequence of Th17 in LN, the released IL-17 signals in FRCs impact LN stromal organization, leading to FRC activation by changing their phenotype from quiescence to highly metabolic. Moreover, the absence of IL-17 signaling in FRCs does not lead to immune failings but does cause impaired B cell responses, due to the reduced availability of BAFF, which is critical for the germinal center formation and maintenance [27].

In metastatic cancer (Figure 2D), FRCs appear to be regulated by the tumor cells. Eom et al. showed in human melanoma that FRCs in tumor-infiltrated LNs may favor cancer invasion and progression through secretion of soluble factors, alterations in the lymph node structure, and by promoting pathological conditions such as fibrosis [20]. Gao et al. also showed in tumor-infiltrated LNs a decrease in FRCs and IL-7 secretion, leading to a declined number and diminished function of T cells in LNs [34].

In homeostasis, as displayed in Figure 2E, FRCs played an important role in secreting homeostatic chemokines, promoting the meeting between $\mathrm{T}$ cells and dendritic cells on the $\mathrm{T}$ cell zone, and also by secreting IL-7, an essential cytokine involved in T cell effector memory differentiation $[2,14,28]$.

Furthermore, in graft versus host disease (GvHD) FRCs' ability for peripheral tissue antigen (PTA) presentation and NOTCH signaling have been shown to be important features in the aggravation and maintenance of the GvHD state (Figure 2F). Dertschnig et al. showed that the loss of PTA presentation by FRCs during GVHD leads to permanent damage in their networks in lymphoid tissues, compromising peripheral tolerance. In addition, they demonstrated that not only the disruption of FCRs occurs during GvHD but also the capacity for the regeneration of this network is impaired, different to what was found for viral infection, where the damage occurs, but after viral clearance, the network is restored [19]. Chung et al. showed that FRC-delivered NOTCH signals through the ligands DLL1 and DLL4 to donor alloreactive T cells help to program the pathogenicity of these T cells. Moreover, they demonstrated that the early use of neutralizing antibodies against DDL1 and DDL4 abrogated GvHD [33]. 
As seen by Kasinath et al. in GN [25], Maaraouf et al., using ischemic reperfusion injury (IRI) with multiple IRI [32], reported that kidney LNs (KLNs) cause excessive deposition of ECM fibers containing fibronectin and collagen, which leads to local fibrosis, similar to kidney fibrosis. They confirmed that depletion of FRCs reduced $\mathrm{T}$ cell activation in the KLNs and ameliorated renal injury in acute IRI [25,32].

Regarding pathway investigation, Knop et al. demonstrated that FRC-derived IL-7 plays an essential role in maintaining central memory $\mathrm{T}$ cells, but is dispensable for naïve $\mathrm{T}$ cell survival [22]. Dubrot et al. showed a mechanism of $\mathrm{T}$ lymphocyte proliferation inhibition by the IFN-y-induced expression of MHC II [30]. In addition, they demonstrated that the deletion of MHC II in LN stromal cells in vivo leads to diminished Treg frequency and functions, and, at the same time, enhances effector cell differentiation, further leading to $\mathrm{T}$ cell tissue infiltration and the subsequent development of $\mathrm{T}$ cell-mediated autoimmunity [30]. Pazstoi et al. used the stromal compartment of gut-draining LNs to demonstrate that FRCs own the tolerogenic capacity that controls $\mathrm{T}$ cells. They also demonstrated that mesenteric LNs (mLNs) are more capable of inducing [35] Treg profiles than the peripheral ones. Likewise, they demonstrated that FRCs contribute to peripheral tolerance by developing de novo Treg by releasing microvesicles (MVEs), which carry high levels of TGF- $\beta$ [35]. Gil-Cruz et al. also used mLNs and Peyer's patches (PP) as the targets of their study and identified that an antiviral response driven by ILC1 and NK was regulated by the FRCs' limiting provision of IL-15 [38]. This mechanism control seems to be activated by TLR7 and/or IL-1 $\beta$, and its control is designated by the MyD88-dependent pathway [38]. Novkovic confirmed that the physical scaffold of LNs formed by the FRC network is critical for the maintenance and functionality of LNs [39], and Takeda et al. demonstrated the role of LPA derived from FRCs in T cell motility [41]. Kelch et al. demonstrated, by imaging, the conduit density in the deep and superficial $\mathrm{T}$ cell zone, concluding that although $\mathrm{T}$ cells within the superficial zone stay in constant contact with FRCs, and in the deep T cell zone, there is a gap that does not guarantee simultaneous contact for all $\mathrm{T}$ cells in this region [26].

In summary, FRCs in homeostasis plays an important role in secreting homeostatic chemokines and IL-7, which are essential for the immune response initiation and for T cell effector memory phenotype differentiation. In a viral setting, FRCs are the main source of IL-33, playing a regulatory role by diminishing the $\mathrm{T}$ cell exhaustion, and acting on $\mathrm{T}$ cell fate through IL-6 secretion. In this same setting, aging FRCs have a negative impact on T cells. In inflammation, FRCs have been proposed to play a dual role by either promoting or inhibiting adaptive immunity. The main mechanisms behind inflammation are related to IFN-y and $\mathrm{PGE}_{2}$-signaling that, in murine cells, release $\mathrm{NO}$ and, in humans, activate IDO. In autoimmunity, the reticular network organization was altered, displayed lower expression of PTAs and podoplanin, and, in this context, IL-17 signaling impacted LN stromal organization, leading to highly metabolically activated FRCs. In metastatic cancer, FRCs appear to be regulated by the tumor cells decreasing IL-7 secretion and enhancing other soluble factors, causing alterations in the lymph node structure, such as fibrosis. In GvHD, the loss of PTA presentation by FRCs leads to permanent damage in their networks, compromising peripheral tolerance.

\section{Conclusions}

These studies reviewed here contributed to the development of deep basic knowledge on immune regulation by FRCs, which seems to be the key to achieving innovative treatments for immune-related diseases and immune-mediated deficiencies. Moreover, these studies have made advances in unveiling cells and molecules that are able to regulate $\mathrm{T}$ cell activation during conditions such as inflammation, viral infection, metastatic cancer, autoimmunity, and GvHD, besides dissecting the pathways in FRCs and the lymph node paracortex structure.

Author Contributions: Conceptualization, B.O.F., M.P.N. and L.F.G.; methodology, B.O.F., M.P.N., G.N.A.R., F.A.O. and L.F.G.; validation, B.O.F., M.P.N., F.A.O., G.N.A.R., L.F.G. and L.M.; formal analysis, B.O.F., M.P.N., L.F.G. and L.M.; investigation, B.O.F., M.P.N., L.F.G. and L.M.; resources, L.M.; 
data curation, L.M. and L.F.G.; writing—original draft preparation, B.O.F., M.P.N., G.N.A.R., L.F.G. and L.M.; writing-review and editing, B.O.F., M.P.N., L.F.G., G.N.A.R. and L.M.; visualization, B.O.F., M.P.N., F.A.O., G.N.A.R., L.F.G. and L.M.; supervision, L.M.; project administration, L.M.; funding acquisition, L.M. All authors have read and agreed to the published version of the manuscript.

Funding: This research was funded by FAPESP (2014/14836-6 and 2018/00094-9) and SisNANO 2.0/MCTIC (442539/2019-3).

Institutional Review Board Statement: Not applicable.

Informed Consent Statement: Not applicable.

Conflicts of Interest: The authors declare no conflict of interest.

\section{References}

1. Denton, A.E.; Carr, E.J.; Magiera, L.P.; Watts, A.J.B.; Fearon, D.T. Embryonic FAP+ lymphoid tissue organizer cells generate the reticular network of adult lymph nodes. J. Exp. Med. 2019, 216, 2242-2252. [CrossRef]

2. Link, A.; Vogt, T.K.; Favre, S.; Britschgi, M.R.; Acha-Orbea, H.; Hinz, B.; Cyster, J.G.; Luther, S.A. Fibroblastic reticular cells in lymph nodes regulate the homeostasis of naive T cells. Nat. Immunol. 2007, 8, 1255-1265. [CrossRef] [PubMed]

3. Sixt, M.; Kanazawa, N.; Selg, M.; Samson, T.; Roos, G.; Reinhardt, D.P.; Pabst, R.; Lutz, M.B.; Sorokin, L. The conduit system transports soluble antigens from the afferent lymph to resident dendritic cells in the T cell area of the lymph node. Immunity 2005, 22, 19-29. [CrossRef]

4. Martinez, V.G.; Pankova, V.; Krasny, L.; Singh, T.; Makris, S.; White, I.J.; Benjamin, A.C.; Dertschnig, S.; Horsnell, H.L.; KristonVizi, J.; et al. Fibroblastic Reticular Cells Control Conduit Matrix Deposition during Lymph Node Expansion. Cell Rep. 2019, 29, 2810-2822. [CrossRef] [PubMed]

5. Luther, S.A.; Vogt, T.K.; Siegert, S. Guiding blind T cells and dendritic cells: A closer look at fibroblastic reticular cells found within lymph node T zones. Immunol. Lett. 2011, 138, 9-11. [CrossRef] [PubMed]

6. Mueller, S.N.; Ahmed, R. Lymphoid stroma in the initiation and control of immune responses. Immunol. Rev. 2008, 224, 284-294. [CrossRef] [PubMed]

7. Alvarenga, H.G.; Marti, L. Multifunctional Roles of Reticular Fibroblastic Cells: More Than Meets the Eye? J. Immunol. Res. 2014, 2014, 402038. [CrossRef] [PubMed]

8. Fletcher, A.L.; Acton, S.E.; Knoblich, K. Lymph node fibroblastic reticular cells in health and disease. Nat. Rev. Immunol. 2015, 15, 350-361. [CrossRef] [PubMed]

9. Severino, P.; Palomino, D.T.; Alvarenga, H.; Almeida, C.B.; Pasqualim, D.C.; Cury, A.; Salvalaggio, P.R.; De Vasconcelos Macedo, A.L.; Andrade, M.C.; Aloia, T.; et al. Human Lymph Node-Derived Fibroblastic and Double-Negative Reticular Cells Alter Their Chemokines and Cytokines Expression Profile Following Inflammatory Stimuli. Front. Immunol. 2017, 8, 141. [CrossRef]

10. Vega, F.; Coombes, K.R.; Thomazy, V.A.; Patel, K.; Lang, W.; Jones, D. Tissue-specific function of lymph node fibroblastic reticulum cells. Pathobiol. J. Immunopathol. Mol. Cell. Biol. 2006, 73, 71-81. [CrossRef]

11. Frontera, V.; Arcangeli, M.L.; Zimmerli, C.; Bardin, F.; Obrados, E.; Audebert, S.; Bajenoff, M.; Borg, J.P.; Aurrand-Lions, M. Cutting edge: JAM-C controls homeostatic chemokine secretion in lymph node fibroblastic reticular cells expressing thrombomodulin. J. Immunol. 2011, 187, 603-607. [CrossRef] [PubMed]

12. Kaldjian, E.P.; Gretz, J.E.; Anderson, A.O.; Shi, Y.; Shaw, S. Spatial and molecular organization of lymph node T cell cortex: A labyrinthine cavity bounded by an epithelium-like monolayer of fibroblastic reticular cells anchored to basement membrane-like extracellular matrix. Int. Immunol. 2001, 13, 1243-1253. [CrossRef] [PubMed]

13. Lukacs-Kornek, V.; Malhotra, D.; Fletcher, A.L.; Acton, S.E.; Elpek, K.G.; Tayalia, P.; Collier, A.-r.; Turley, S.J. Regulated release of nitric oxide by nonhematopoietic stroma controls expansion of the activated T cell pool in lymph nodes. Nat. Immunol. 2011, 12, 1096-1104. [CrossRef] [PubMed]

14. Fletcher, A.L.; Malhotra, D.; Turley, S.J. Lymph node stroma broaden the peripheral tolerance paradigm. Trends Immunol. 2011, 32, 12-18. [CrossRef] [PubMed]

15. Gardner, J.M.; Devoss, J.J.; Friedman, R.S.; Wong, D.J.; Tan, Y.X.; Zhou, X.; Johannes, K.P.; Su, M.A.; Chang, H.Y.; Krummel, M.F.; et al. Deletional tolerance mediated by extrathymic Aire-expressing cells. Science 2008, 321, 843-847. [CrossRef] [PubMed]

16. Nadafi, R.; Gago de Graça, C.; Keuning, E.D.; Koning, J.J.; de Kivit, S.; Konijn, T.; Henri, S.; Borst, J.; Reijmers, R.M.; van Baarsen, L.G.M.; et al. Lymph Node Stromal Cells Generate Antigen-Specific Regulatory T Cells and Control Autoreactive T and B Cell Responses. Cell Rep. 2020, 30, 4110-4123. [CrossRef]

17. Krausgruber, T.; Fortelny, N.; Fife-Gernedl, V.; Senekowitsch, M.; Schuster, L.C.; Lercher, A.; Nemc, A.; Schmidl, C.; Rendeiro, A.F.; Bergthaler, A.; et al. Structural cells are key regulators of organ-specific immune responses. Nature 2020, 583, 296-302. [CrossRef] [PubMed]

18. Aparicio-Domingo, P.; Cannelle, H.; Buechler, M.B.; Nguyen, S.; Kallert, S.M.; Favre, S.; Alouche, N.; Papazian, N.; Ludewig, B.; Cupedo, T.; et al. Fibroblast-derived IL-33 is dispensable for lymph node homeostasis but critical for CD8 T-cell responses to acute and chronic viral infection. Eur. J. Immunol. 2020, 51, 76-90. [CrossRef] 
19. Dertschnig, S.; Evans, P.; Santos, E.S.P.; Manzo, T.; Ferrer, I.R.; Stauss, H.J.; Bennett, C.L.; Chakraverty, R. Graft-versus-host disease reduces lymph node display of tissue-restricted self-antigens and promotes autoimmunity. J. Clin. Investig. 2020, 130, $1896-1911$. [CrossRef]

20. Eom, J.; Park, S.M.; Feisst, V.; Chen, C.J.J.; Mathy, J.E.; McIntosh, J.D.; Angel, C.E.; Bartlett, A.; Martin, R.; Mathy, J.A.; et al. Distinctive Subpopulations of Stromal Cells Are Present in Human Lymph Nodes Infiltrated with Melanoma. Cancer Immunol. Res. 2020, 8, 990-1003. [CrossRef] [PubMed]

21. Gonzalez Badillo, F.; Zisi Tegou, F.; Masina, R.; Wright, S.; Scully, M.; Harwell, L.; Lupp, M.; Postigo-Fernandez, J.; Creusot, R.J.; Tomei, A.A. Tissue-Engineered Stromal Reticula to Study Lymph Node Fibroblastic Reticular Cells in Type I Diabetes. Cell. Mol. Bioeng. 2020, 13, 419-434. [CrossRef] [PubMed]

22. Knop, L.; Deiser, K.; Bank, U.; Witte, A.; Mohr, J.; Philipsen, L.; Fehling, H.J.; Müller, A.J.; Kalinke, U.; Schüler, T. IL-7 derived from lymph node fibroblastic reticular cells is dispensable for naive $\mathrm{T}$ cell homeostasis but crucial for central memory $\mathrm{T}$ cell survival. Eur. J. Immunol. 2020, 50, 846-857. [CrossRef] [PubMed]

23. Perez-Shibayama, C.; Islander, U.; Lütge, M.; Cheng, H.W.; Onder, L.; Ring, S.S.; de Martin, A.; Novkovic, M.; Colston, J.; Gil-Cruz, C.; et al. Type I interferon signaling in fibroblastic reticular cells prevents exhaustive activation of antiviral CD8+ T cells. Sci. Immunol. 2020, 5. [CrossRef] [PubMed]

24. Brown, F.D.; Sen, D.R.; LaFleur, M.W.; Godec, J.; Lukacs-Kornek, V.; Schildberg, F.A.; Kim, H.J.; Yates, K.B.; Ricoult, S.J.H.; Bi, K.; et al. Fibroblastic reticular cells enhance T cell metabolism and survival via epigenetic remodeling. Nat. Immunol. 2019, 20, 1668-1680. [CrossRef]

25. Kasinath, V.; Yilmam, O.A.; Uehara, M.; Jiang, L.; Ordikhani, F.; Li, X.; Salant, D.J.; Abdi, R. Activation of fibroblastic reticular cells in kidney lymph node during crescentic glomerulonephritis. Kidney Int. 2019, 95, 310-320. [CrossRef]

26. Kelch, I.D.; Bogle, G.; Sands, G.B.; Phillips, A.R.J.; LeGrice, I.J.; Dunbar, P.R. High-resolution 3D imaging and topological mapping of the lymph node conduit system. PLoS Biol. 2019, 17, e3000486. [CrossRef] [PubMed]

27. Majumder, S.; Amatya, N.; Revu, S.; Jawale, C.V.; Wu, D.; Rittenhouse, N.; Menk, A.; Kupul, S.; Du, F.; Raphael, I.; et al. IL-17 metabolically reprograms activated fibroblastic reticular cells for proliferation and survival. Nat. Immunol. 2019, 20, 534-545. [CrossRef]

28. Masters, A.R.; Hall, A.; Bartley, J.M.; Keilich, S.R.; Lorenzo, E.C.; Jellison, E.R.; Puddington, L.; Haynes, L. Assessment of Lymph Node Stromal Cells as an Underlying Factor in Age-Related Immune Impairment. J. Gerontol. Ser. A Biol. Sci. Med. Sci. 2019, 74, 1734-1743. [CrossRef]

29. Schaeuble, K.; Cannelle, H.; Favre, S.; Huang, H.Y.; Oberle, S.G.; Speiser, D.E.; Zehn, D.; Luther, S.A. Attenuation of chronic antiviral T-cell responses through constitutive COX2-dependent prostanoid synthesis by lymph node fibroblasts. PLoS Biol. 2019, 17, e3000072. [CrossRef]

30. Dubrot, J.; Duraes, F.V.; Harlé, G.; Schlaeppi, A.; Brighouse, D.; Madelon, N.; Göpfert, C.; Stokar-Regenscheit, N.; Acha-Orbea, H.; Reith, W.; et al. Absence of MHC-II expression by lymph node stromal cells results in autoimmunity. Life Sci. Alliance 2018, 1, e201800164. [CrossRef]

31. Knoblich, K.; Cruz Migoni, S.; Siew, S.M.; Jinks, E.; Kaul, B.; Jeffery, H.C.; Baker, A.T.; Suliman, M.; Vrzalikova, K.; Mehenna, H.; et al. The human lymph node microenvironment unilaterally regulates T-cell activation and differentiation. PLoS Biol. 2018, 16, e2005046. [CrossRef]

32. Maarouf, O.H.; Uehara, M.; Kasinath, V.; Solhjou, Z.; Banouni, N.; Bahmani, B.; Jiang, L.; Yilmam, O.A.; Guleria, I.; Lovitch, S.B.; et al. Repetitive ischemic injuries to the kidneys result in lymph node fibrosis and impaired healing. JCI Insight 2018, 3. [CrossRef] [PubMed]

33. Chung, J.; Ebens, C.L.; Perkey, E.; Radojcic, V.; Koch, U.; Scarpellino, L.; Tong, A.; Allen, F.; Wood, S.; Feng, J.; et al. Fibroblastic niches prime T cell alloimmunity through Delta-like Notch ligands. J. Clin. Investig. 2017, 127, 1574-1588. [CrossRef] [PubMed]

34. Gao, J.; Zhao, L.; Liu, L.; Yang, Y.; Guo, B.; Zhu, B. Disrupted fibroblastic reticular cells and interleukin-7 expression in tumor draining lymph nodes. Oncol. Lett. 2017, 14, 2954-2960. [CrossRef]

35. Pasztoi, M.; Pezoldt, J.; Beckstette, M.; Lipps, C.; Wirth, D.; Rohde, M.; Paloczi, K.; Buzas, E.I.; Huehn, J. Mesenteric lymph node stromal cell-derived extracellular vesicles contribute to peripheral de novo induction of Foxp3(+) regulatory T cells. Eur. J. Immunol. 2017, 47, 2142-2152. [CrossRef] [PubMed]

36. Valencia, J.; Jiménez, E.; Martínez, V.G.; Del Amo, B.G.; Hidalgo, L.; Entrena, A.; Fernández-Sevilla, L.M.; Del Río, F.; Varas, A.; Vicente, Á.; et al. Characterization of human fibroblastic reticular cells as potential immunotherapeutic tools. Cytotherapy 2017, 19, 640-653. [CrossRef]

37. Yu, M.; Guo, G.; Zhang, X.; Li, L.; Yang, W.; Bollag, R.; Cui, Y. Fibroblastic reticular cells of the lymphoid tissues modulate T cell activation threshold during homeostasis via hyperactive cyclooxygenase-2/prostaglandin E(2) axis. Sci. Rep. 2017, 7, 3350. [CrossRef]

38. Gil-Cruz, C.; Perez-Shibayama, C.; Onder, L.; Chai, Q.; Cupovic, J.; Cheng, H.W.; Novkovic, M.; Lang, P.A.; Geuking, M.B.; McCoy, K.D.; et al. Fibroblastic reticular cells regulate intestinal inflammation via IL-15-mediated control of group 1 ILCs. Nat. Immunol. 2016, 17, 1388-1396. [CrossRef]

39. Novkovic, M.; Onder, L.; Cupovic, J.; Abe, J.; Bomze, D.; Cremasco, V.; Scandella, E.; Stein, J.V.; Bocharov, G.; Turley, S.J.; et al. Topological Small-World Organization of the Fibroblastic Reticular Cell Network Determines Lymph Node Functionality. PLoS Biol. 2016, 14, e1002515. [CrossRef] 
40. Royer, D.J.; Conrady, C.D.; Carr, D.J. Herpesvirus-Associated Lymphadenitis Distorts Fibroblastic Reticular Cell Microarchitecture and Attenuates CD8 T Cell Responses to Neurotropic Infection in Mice Lacking the STING-IFN $\alpha / \beta$ Defense Pathways. J. Immunol. 2016, 197, 2338-2352. [CrossRef]

41. Takeda, A.; Kobayashi, D.; Aoi, K.; Sasaki, N.; Sugiura, Y.; Igarashi, H.; Tohya, K.; Inoue, A.; Hata, E.; Akahoshi, N.; et al. Fibroblastic reticular cell-derived lysophosphatidic acid regulates confined intranodal T-cell motility. eLife 2016, 5, e10561. [CrossRef] [PubMed]

42. Liberati, A.; Altman, D.G.; Tetzlaff, J.; Mulrow, C.; Gotzsche, P.C.; Ioannidis, J.P.; Clarke, M.; Devereaux, P.J.; Kleijnen, J.; Moher, D. The PRISMA statement for reporting systematic reviews and meta-analyses of studies that evaluate health care interventions: Explanation and elaboration. PLoS Med. 2009, 6, e1000100. [CrossRef]

43. Krishnamurty, A.T.; Turley, S.J. Lymph node stromal cells: Cartographers of the immune system. Nat. Immunol. 2020, 21, 369-380. [CrossRef] [PubMed]

44. Talemi, S.R.; Höfer, T. Antiviral interferon response at single-cell resolution. Immunol. Rev. 2018, 285, 72-80. [CrossRef] [PubMed]

45. Hunter, C.A.; Jones, S.A. IL-6 as a keystone cytokine in health and disease. Nat. Immunol. 2015, 16, 448-457. [CrossRef] [PubMed]

46. Chai, Q.; Onder, L.; Scandella, E.; Gil-Cruz, C.; Perez-Shibayama, C.; Cupovic, J.; Danuser, R.; Sparwasser, T.; Luther, S.A.; Thiel, $\mathrm{V}$; ; et al. Maturation of lymph node fibroblastic reticular cells from myofibroblastic precursors is critical for antiviral immunity. Immunity 2013, 38, 1013-1024. [CrossRef]

47. Thompson, H.L.; Smithey, M.J.; Uhrlaub, J.L.; Jeftić, I.; Jergović, M.; White, S.E.; Currier, N.; Lang, A.M.; Okoye, A.; Park, B.; et al. Lymph nodes as barriers to T-cell rejuvenation in aging mice and nonhuman primates. Aging Cell 2019, 18, e12865. [CrossRef]

48. Mueller, S.N.; Matloubian, M.; Clemens, D.M.; Sharpe, A.H.; Freeman, G.J.; Gangappa, S.; Larsen, C.P.; Ahmed, R. Viral targeting of fibroblastic reticular cells contributes to immunosuppression and persistence during chronic infection. Proc. Natl. Acad. Sci. USA 2007, 104, 15430-15435. [CrossRef]

49. Zeng, M.; Smith, A.J.; Wietgrefe, S.W.; Southern, P.J.; Schacker, T.W.; Reilly, C.S.; Estes, J.D.; Burton, G.F.; Silvestri, G.; Lifson, J.D.; et al. Cumulative mechanisms of lymphoid tissue fibrosis and T cell depletion in HIV-1 and SIV infections. J. Clin. Investig. 2011, 121, 998-1008. [CrossRef]

50. Malhotra, D.; Fletcher, A.L.; Turley, S.J. Stromal and hematopoietic cells in secondary lymphoid organs: Partners in immunity. Immunol. Rev. 2013, 251, 160-176. [CrossRef]

51. Siegert, S.; Luther, S.A. Positive and negative regulation of $\mathrm{T}$ cell responses by fibroblastic reticular cells within paracortical regions of lymph nodes. Front. Immunol. 2012, 3, 285. [CrossRef] [PubMed]

52. Postigo-Fernandez, J.; Farber, D.L.; Creusot, R.J. Phenotypic alterations in pancreatic lymph node stromal cells from human donors with type 1 diabetes and NOD mice. Diabetologia 2019, 62, 2040-2051. [CrossRef] [PubMed] 